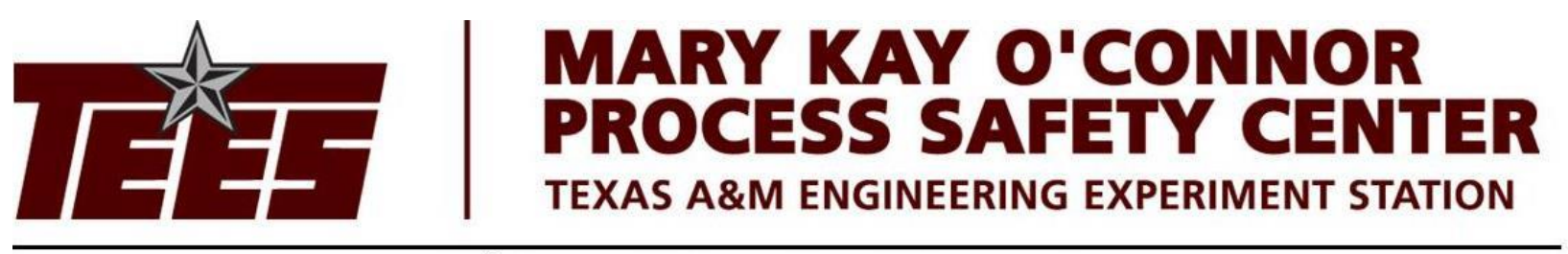

$19^{\text {th }}$ Annual International Symposium

October 25-27, 2016 • College Station, Texas

\title{
Large Scale Detonation Testing: New Findings in the prediction of DDTs at large scales
}

\author{
Scott Davis ${ }^{1}$, Erik Merilo ${ }^{2}$, Derek Engel ${ }^{1}$, Kees van Wingerden ${ }^{1}$ \\ ${ }^{1}$ Gexcon US, Bethesda, Maryland, USA \\ ${ }^{2}$ SRI International, Menlo Park, CA, USA \\ sgdavis@gexcon.com
}

\begin{abstract}
A large vapor cloud explosion (VCE) followed by a fire is one of the most dangerous and high-consequence events that can occur at petrochemical facilities. As the size and complexity of facilities increase, designs must consider the potential adverse effects associated with vapor cloud explosions in large congested areas and understand the potential for more devastating deflagration-to-detonation transitions (DDTs) on these facilities. While the likelihood of DDTs is lower than deflagrations, they have been identified in some of the most recent large-scale explosion incidents including: 2005 Buncefield explosion, 2009 San Juan explosion, and 2009 Jaipur event. The consequences of DDTs can be orders of magnitude larger than deflagration because they have the ability to self-propagate outside the region of high congestion/confinement. Hence, it is critical to understand how a facility's geometry or equipment layout can affect explosion consequences and assist in their mitigation and/or prevention.
\end{abstract}

Due to the inability to predict such devastating phenomena on the large scale, owners and designers cannot evaluate installations for risk of DDTs and provide "inherently safer" layout or mitigation measures to significantly reduce or eliminate such hazards. However, there is a lack of data at the large scale to validate the necessary design tools used to predict the risk of DDT. One of the main goals of this research project is to provide large scale DDT explosion data and validate the tools necessary to predict vapor cloud explosions in early design phase.

This paper will present the results of large scale testing being conducted in a newly developed test rig of $50,000 \mathrm{ft}^{3}\left(1,500 \mathrm{~m}^{3}\right)$ gross volume under award Subcontract 12121-6403-01 provided by the Research Partnership to Secure Energy for America (RPSEA). These tests involve evaluation of deflagrations and DDTs involving stoichiometric, lean and rich mixtures, with propane and methane fuels. The effectiveness of mitigation techniques such as solid inhibitors or deluge is evaluated for preventing DDTs.

\section{INTRODUCTION}

A large vapor cloud explosion (VCE) followed by a fire is one of the most dangerous and highconsequence events that can occur. As the size and complexity of facilities increase, designs must consider the potential adverse effects associated with vapor cloud explosions in large congested areas. However, one of the most devastating explosions is when the subsonic deflagration transitions to a supersonic flame front, which can travel at speeds greater than $1700 \mathrm{~m} / \mathrm{s}$ (3,800 miles per hour) and pressures greater than $17 \mathrm{barg}$ ( $250 \mathrm{psig}$ ). This phenomenon is called a deflagration-to-detonation transition (DDT), whereby the resulting detonation velocities are of the same order as high order explosives. In addition, the resulting damage from such events can be quite devastating to plants and personnel. 
While the likelihood of DDTs is lower than deflagrations, they have been identified in some of the most recent large-scale explosion incidents including: 2004 Skikda explosion, 2005 Buncefield explosion ${ }^{1,2}$, 2009 San Juan explosion ${ }^{3}$, and 2009 Jaipur event $^{4}$. The consequences of DDTs can be orders of magnitude larger than deflagrations because they have the ability to self-propagate outside the region of high congestion/confinement and blast overpressures can be up to two orders of magnitude higher for a DDT. For example, Figure 1 and Figure 2 show evidence of extremely high overpressures observed in the Skikda, Algeria explosion in an LNG liquefaction plant. Figure 3 and Figure 4 show the devastating damage observed in the 2005 explosion in the Buncefield fuel depot. Due to the inability to predict such devastating phenomena on the large scale, owners and designers cannot evaluate installations for risk of DDTs and provide "inherently safer" layout or mitigation measures to significantly reduce or eliminate such hazards.

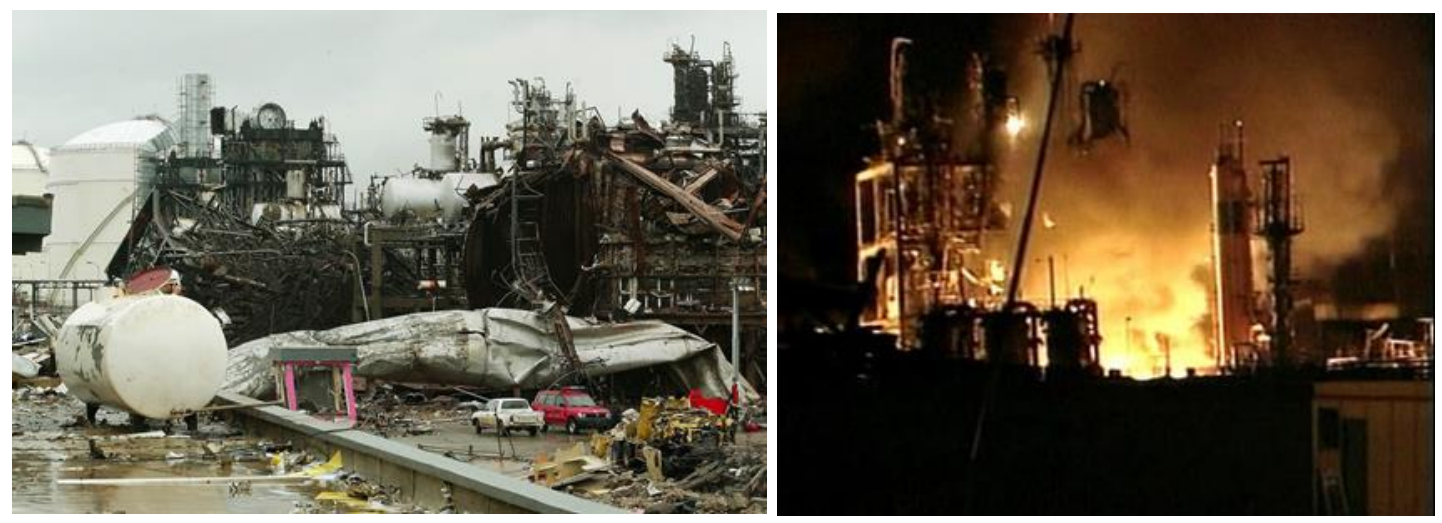

Figure 1-Images of the 2004 explosion and ensuing fire at the Skikda LNG liquefaction facility.
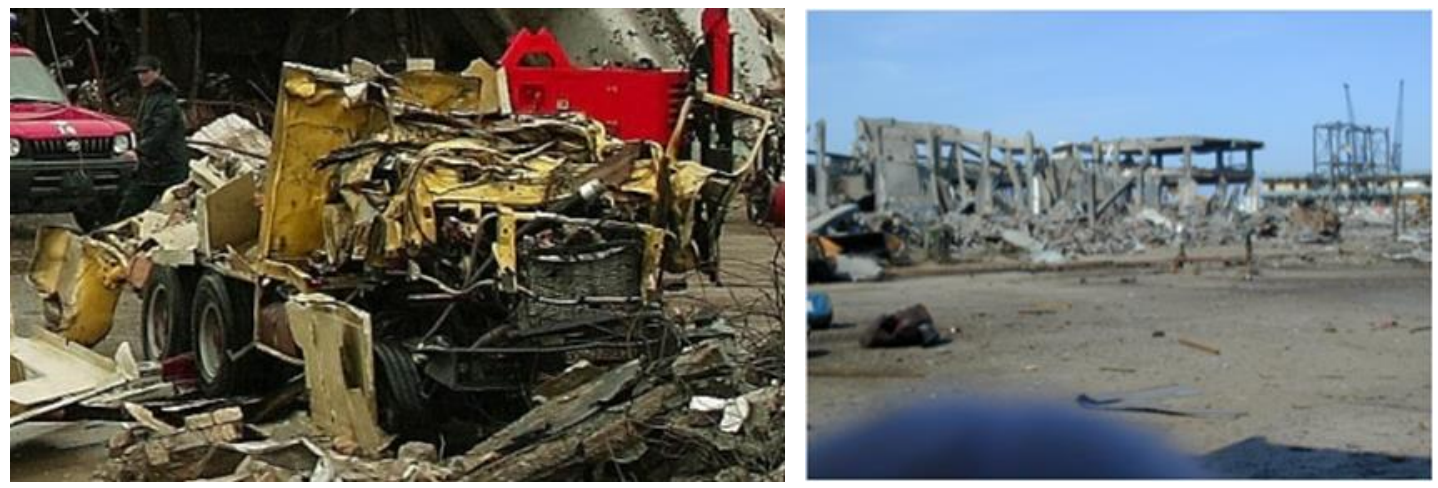

Figure 2- Images of the damage from the 2004 Skikda explosion: left image - truck, right image - maintenance building.
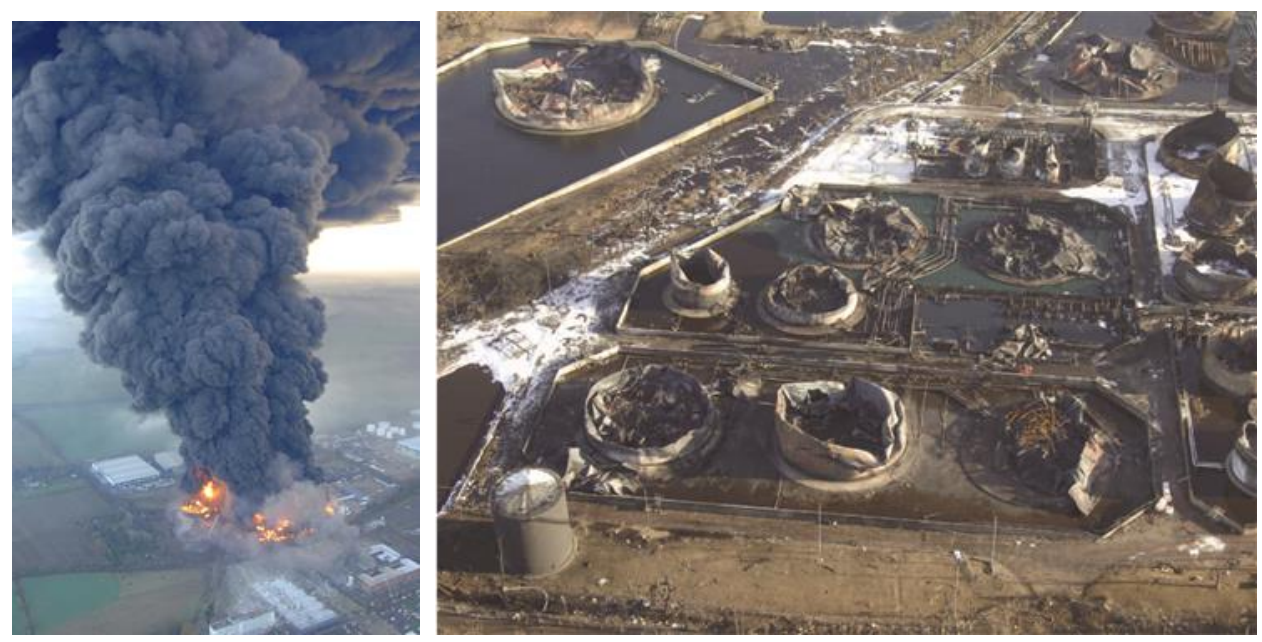

Figure 3-Images of the 2005 explosion and ensuing fire at the Buncefield tank farm. 

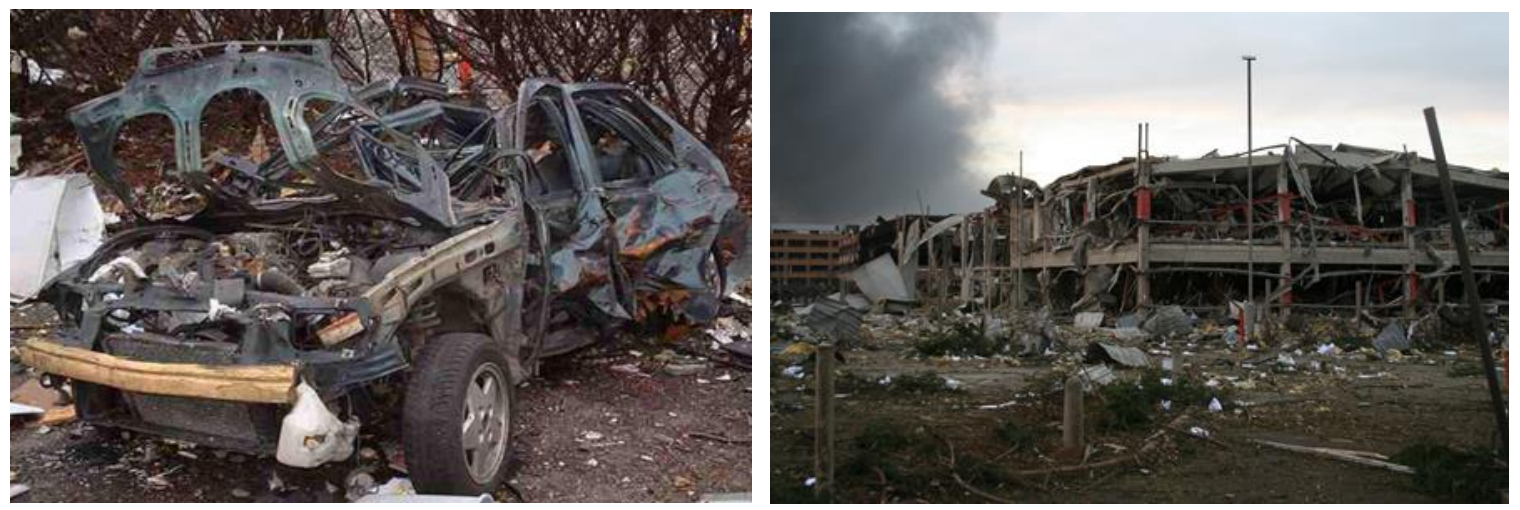

Figure 4-Images of the damage from the 2005 Buncefield explosion: left image - automobile, right image - Fuji building.

The inability to predict such phenomena becomes increasingly problematic as the size and complexity of facilities increases. Designs must consider the potential adverse effects associated with vapor cloud explosions in large congested areas and understand the potential for more devastating deflagration-todetonation transitions (DDTs) within these facilities. Hence, it is critical to understand how a facility's geometry or equipment layout can affect explosion consequences and assist in their mitigation and/or prevention.

In order to achieve such goals, Gexcon has performed large-scale experiments to validate DDT onset prediction and active mitigation at scales relevant to large-scale designs. These studies will and are being used to further validate and develop industry-accepted CFD tools and simplified methods, which are currently used to assess the consequences of explosions in the oil/gas industry ${ }^{5,6,7}$. Gexcon, who has teamed with SRI, was awarded Subcontract 12121-6403-01 under the Research Partnership to Secure Energy for America (RPSEA), whereby the objectives of this project was to: (1) improve, adapt, and validate the tools necessary to predict high consequence events early in the design phase of facilities and (2) providing guidance and recommended practices to facility owners and designers which, when utilized, will help minimize and design against the consequences of fire/explosion incidents.

\section{APPROACH}

To facilitate the design of "inherently safer" facilities, we need to be able to predict high consequence events for vapor cloud explosions and evaluate how design changes affect the possible consequences. Determining whether a deflagration-to-detonation transition (DDT) can occur is imperative for accurate calculation of such events. Currently, there is a lack of adequate tools that can predict DDT. To address this problem, Gexcon US teamed with SRI International to further develop and validate the DDT onset prediction capability of Gexcon's FLACS CFD package and other analytical tools, and to investigate mitigation techniques that can reduce the consequences of VCEs in petrochemical facilities through largescale experimental testing.

Figure 5 illustrates our basic approach. We are currently working on validating FLACS and other analytical tool's DDT onset prediction capabilities for scales and geometries relevant to large-scale petrochemical installations. FLACS is a commercially available code that is currently used by over 100 companies. To judge the likelihood of a DDT occurring during a deflagration event in a congested environment FLACS monitors the spatial pressure gradient across the flame front at any location at any moment. The value of this spatial pressure gradient is normalized using the grid resolution and initial pressure reading:

$$
\left.\frac{d P}{d x}\right|_{\text {normalized }}=\left.\frac{d P}{d x}\right|_{\text {actual }} \frac{X_{C V}}{P_{0}}
$$

Equation 1 
where $P_{0}$ is the initial pressure and $X_{C V}$ represents the grid resolution. A magnitude of the pressure gradients of order 1 indicates that DDT is likely, with values around 10 or larger indicating a strong possibility of $\mathrm{DDT}^{8,9}$.

In order to achieve the goal of validation, we have developed a large-scale test facility of approximately $1,500 \mathrm{~m}^{3}\left(50,000 \mathrm{ft}^{3}\right)$ gross volume at a joint Gexcon/SRI test site to study the potential of DDT for gases of varying reactivity (i.e., methane and propane) and will utilize the large-scale experimental data for FLACS, and other analytical tool's, validation. The tests were conducted with various levels of congestion, confinement, and gas concentrations. The flame speed and overpressure measurements continue to be used for validation. Also, tests were performed that utilize mitigation measures (e.g., solid inhibitor) to reduce the explosion consequences.

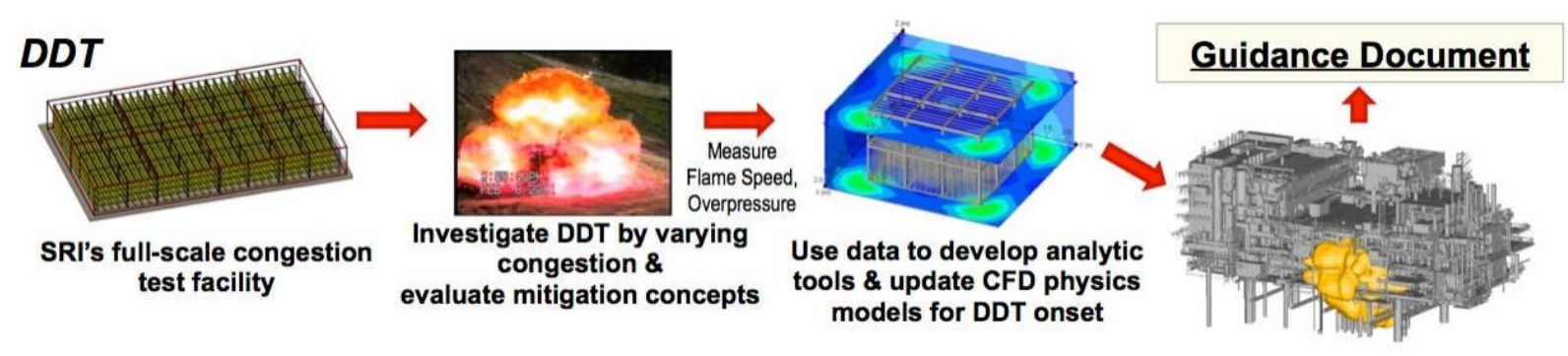

Figure 5-The Gexcon/SRI approach to update and validate the tools for predicting DDT onset.

\section{DDT TEST DATA AND RESULTS \\ Testing Setup}

Gexcon combined with SRI to develop a joint large-scale explosion area at SRI's 480 acre CHES site in California. A large-scale test pad was constructed in January 2015, which covered a test area approximately $10 \mathrm{~m} \times 60 \mathrm{~m}(30 \mathrm{ft} \times 200 \mathrm{ft})$. An overview can be found in Figure 6. This test pad was designed for continued use after the RPSEA test matrix. Several thermocouples are also embedded within the concrete for use in potential spill tests in the future. The testing site also includes adjacent open area for supplemental testing to be conducted regarding exposure to overpressure events. This could include testing of structural response of elements exposed to overpressure or similar tests for near-field overpressure exposure.

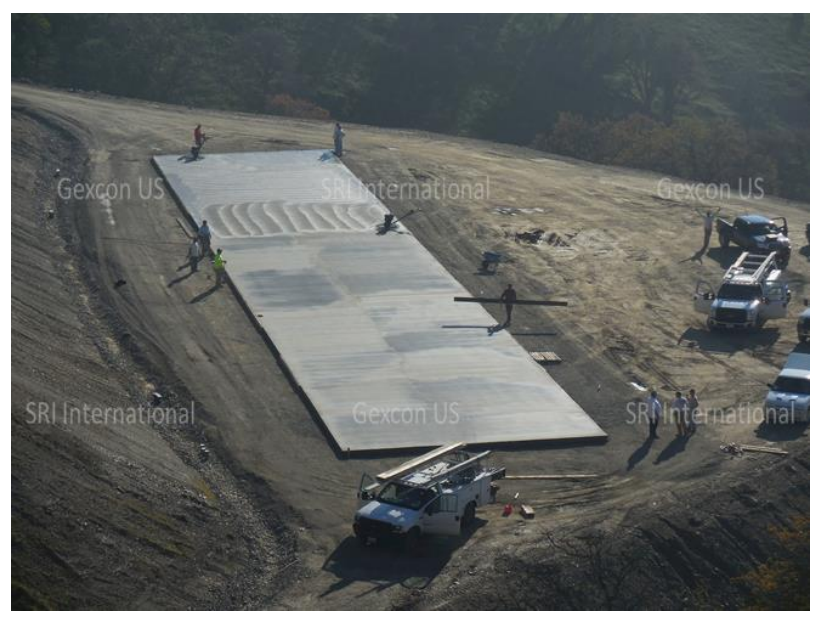

Figure 6-SRI Test Pad.

As part of the testing plan, Gexcon and SRI developed a modular test assembly. This allowed for extensive flexibility in the testing, whereby congestion levels and congestion orientations could easily be modified within the rig. Several design iterations were evaluated to ensure the durability of the rig. The modules were placed in an array for testing with 2 modules across, 15 modules deep and 1 module high as shown in 
Figure 7. The rigs were designed using Finite Element Analysis to ensure the structure could withstand numerous DDT events without permanent deformation or damage.

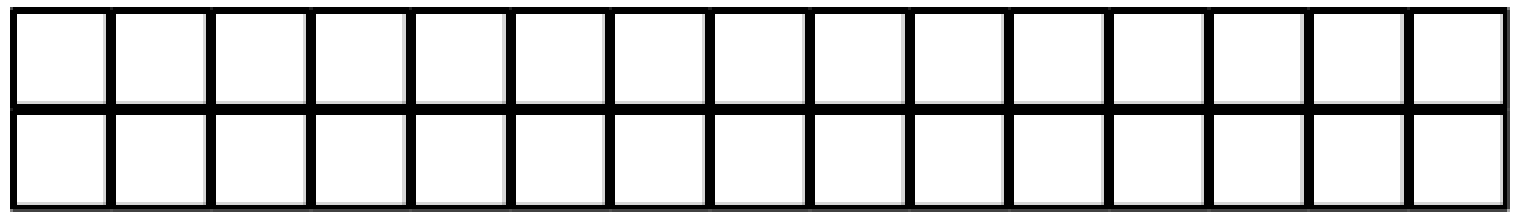

Figure 7- Schematic of assembled rig array.

To assist in understanding the size of these modules and the final test volume, please refer to pictures below (Figure 8 and Figure 9) of the modules during construction and final assembly onsite. As the goal of the project was to easily modify congestion levels and congestion orientations within the rig, hundreds of approximately 7-inch and 2-inch pipes were purchased and delivered to the test site (see Figure 8). These pipes allowed the modules to have a variable congestion level and were added for the final tests outlined in the test matrix with a "high" congestion configuration.
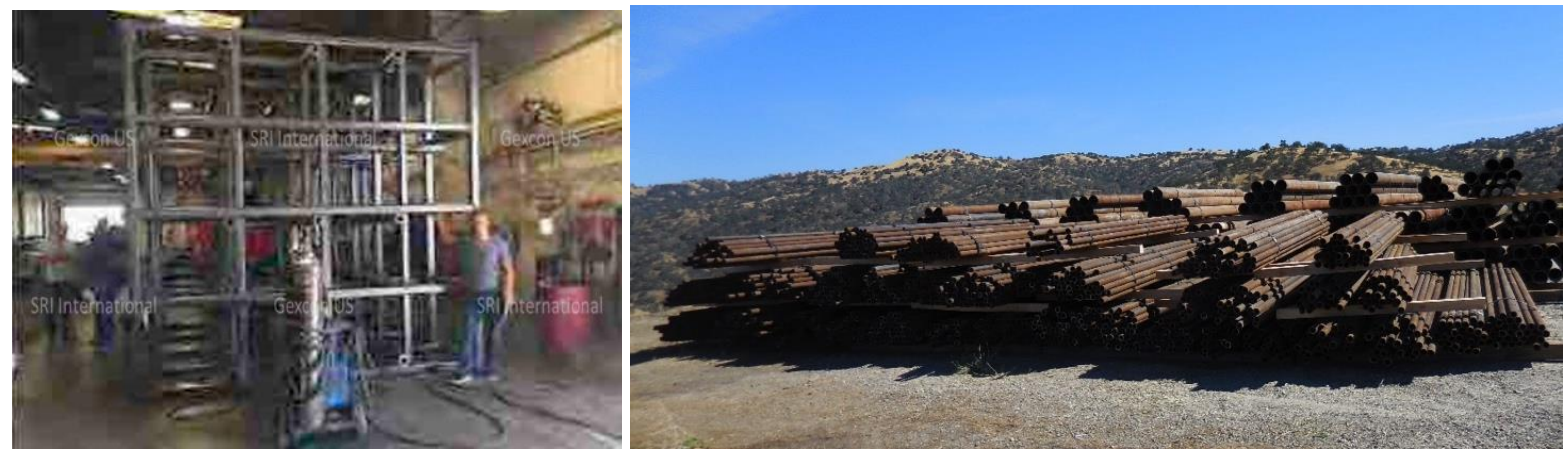

Figure 8-Modules being constructed.
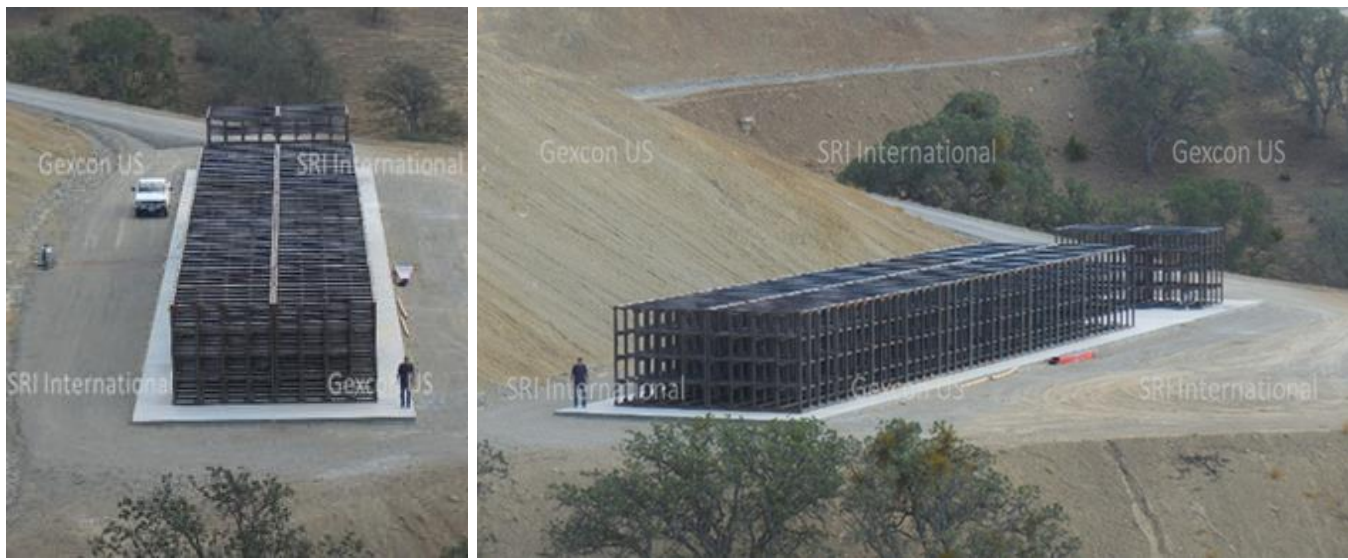

Figure 9-Finalized modules on the test site.

A single polyethylene sheet of either 0.05 or $0.1 \mathrm{~mm}(0.002$ or $0.004 \mathrm{in})$ thickness covering the modules was used to retain the gas/air mixture prior to ignition. A steel plate was welded along the upper and lower most structural elements, and ran the entire length of the module assembly. The polyethylene sheet was secured directly to the modules along these plates. Some tests were performed with a tent cutting apparatus to account for any variation in results due to the initial confinement the sheeting provided. An electric spark was used as the ignition source and was located approximately half a module length within the structure, centered and at mid-module height. 
Gas was introduced into the rig at four separate locations and mixed thoroughly with numerous box fans. Samples were extracted at 8 locations throughout the rig, with half the sample points being located in the upper section and half near ground level. The extracted samples were sequentially pumped to an IR gas analyzer (IR4800D three channel), which was calibrated prior to the test. Tests included commercial grade propane (HD-5, >95\% purity), experimental grade propane ( $>97.5 \%$ purity) and methane. After uniform concentrations were established in the rig, the fans were stopped for 2 minutes (with the exception of Test \#8), after which the mixture was ignited.

The flame progression was captured using two to three high-speed video cameras (Phantom V7.2) and two normal speed cameras. One set of high-speed and normal speed cameras was located perpendicular to the propagation direction of the flame located and the other set just offset of the parallel axis (see Figure 10). The high-speed video was run typically at $10,000 \mathrm{fps}$ (40 $\square \mathrm{sec}$ exposure) and was used to determine flame arrival and flame speed for the tests. Test \#6 and beyond included an additional high-speed camera setup for a close-up view of the initial flame development in the first few rows of modules. The high-speed video data is used to provide a very accurate flame-front location as a function of time from which the flame speed can be determined.

Thirteen ionization pins were also utilized to capture the flame propagation within the modules as shown in Figure 11. Upon flame arrival, the presence of ions in the reaction zone lowers the resistance across the sensor gap initiating a capacitive discharge where the resulting transient voltage is detected. Ideally the time of arrival measurements between successive pins can be used to determine the flame speed.

The overpressure development within the test rig polyethylene enclosure was measured using 13 pressure transducers located along the major axis, nominally flush with ground level and coupled with the ion pins within the rig (see Figure 11). There are 4 other pressure transducers outside the rig, two along the major axis and two perpendicular to the anticipated DDT location (not pictured). PCB types 113A36 and 112M343 pressure transducers with built-in FET amplifiers were used. The 113A36 type has a range of 034.5 bar and a response time of $1 \mu \mathrm{s}$, while the 112M343 has a range of 0-6.9 bar and a response time of 2 $\mu \mathrm{s}$. The modules start with row four (as shown in Figure 11) for test numbers 5 through 8 and 12 due to a 24 modules configuration being used out of a possible 30. An additional pressure transducer and ionization pin was placed in module row number two during the full 30 module tests. Two weather stations (Davis 6152 Vantage Pro 2) were utilized at the test site to record, temperature, wind speed, wind direction and humidity at the time of the test.

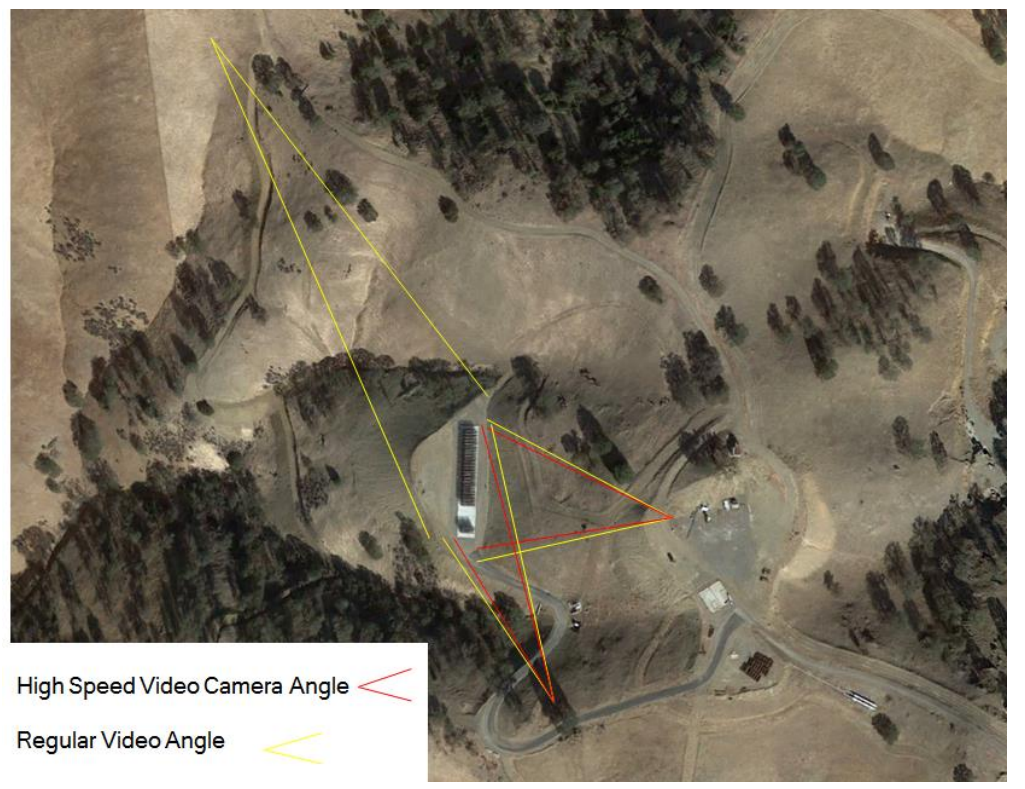

Figure 10-High speed camera angles in red, regular speed in orange. 


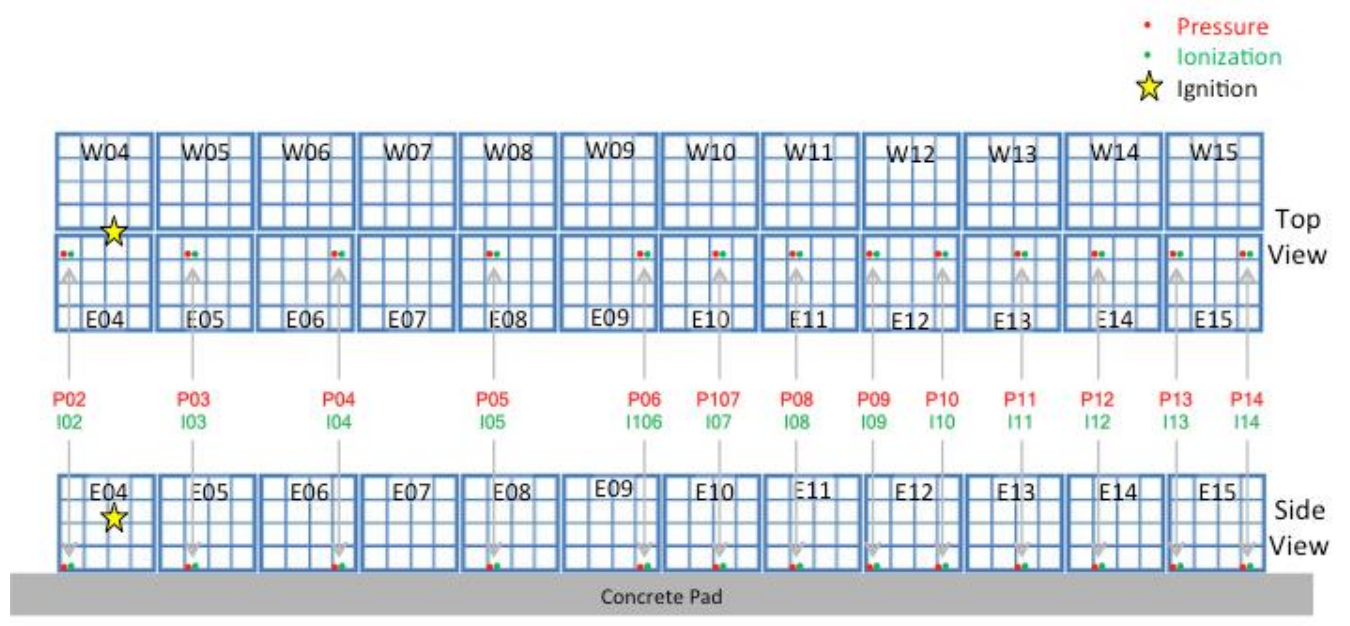

Figure 11-Layout of the 13 ion pins and pressure sensors internal to the modules. Four additional pressure sensors were located outside the structure.

Testing is ongoing to evaluate two fuels of varying reactivity under two levels of congestions. The test outline includes repeat tests to validate the experimental outcome. The test matrix is shown in Table 1.

Table 1 -Test matrix.

\begin{tabular}{|c|c|c|c|c|c|c|}
\hline $\begin{array}{c}\text { Test } \\
\#\end{array}$ & Fuel & $\begin{array}{c}\text { Equivalence } \\
\text { Ratio }\end{array}$ & $\begin{array}{c}\text { Plastic } \\
\text { Thickness } \\
\text { (mils) }\end{array}$ & $\begin{array}{l}\text { Rig Size } \\
\text { (modules) }\end{array}$ & Congestion & Notes \\
\hline 5 & $\begin{array}{l}\text { Propane } \\
(94.58 \%)\end{array}$ & 1.15 & 4 & 24 & Low & \\
\hline 6 & $\begin{array}{l}\text { Propane } \\
(95.23 \%)\end{array}$ & 1.18 & 4 & 24 & Low & \\
\hline 7 & $\begin{array}{l}\text { Propane } \\
(95.23 \%)\end{array}$ & & $\begin{array}{c}2 \text { on first } \\
\text { three rows } \\
4 \text { mils }\end{array}$ & 24 & Low & \\
\hline 8 & $\begin{array}{l}\text { Propane } \\
(97.56 \%)\end{array}$ & 1.04 & 2 & 24 & Low & $\begin{array}{c}\text { Circulator fans } \\
\text { left on }\end{array}$ \\
\hline 9 & $\begin{array}{c}\text { UHP } \\
\text { Methane }\end{array}$ & 0.92 & 2 & 30 & Low & \\
\hline 10 & $\begin{array}{l}\text { Propane } \\
(97.56 \%)\end{array}$ & 0.81 & 2 & 30 & Low & \\
\hline 11 & $\begin{array}{l}\text { Propane } \\
(97.56 \%)\end{array}$ & 1.35 & 2 & 30 & Low & \\
\hline 12 & $\begin{array}{l}\text { Propane } \\
(97.56 \%)\end{array}$ & 1.09 & 2 & 24 & Low & Cut Tent \\
\hline 13 & $\begin{array}{c}\text { UHP } \\
\text { Methane }\end{array}$ & 1.05 & $\begin{array}{c}4 \text { on top and } \\
\text { edges, } \\
2 \text { on sides }\end{array}$ & 30 & High & Cut Tent \\
\hline 14 & Propane & 0.90 & & 30 & High & \\
\hline 15 & Propane & 1.35 & & 30 & High & \\
\hline 16 & $\begin{array}{c}\text { UHP } \\
\text { Methane }\end{array}$ & 1.05 & & 30 & High & $\begin{array}{l}\text { Mitigation agent } \\
\text { added }\end{array}$ \\
\hline 17 & $\begin{array}{c}\text { UHP } \\
\text { Methane }\end{array}$ & 1.06 & & 14 & High & $\begin{array}{l}\text { Mitigation agent } \\
\text { added }\end{array}$ \\
\hline
\end{tabular}




\section{Test Results}

The first two tests (tests \#5 and \#6) were conducted with 24 modules (two modules wide and 12 long) and with commercial grade propane (HD-5) as a fuel. The gross volume for these tests was approximately $1,200 \mathrm{~m}^{3}\left(42,000 \mathrm{ft}^{3}\right)$ with dimensions of approximately $8 \mathrm{~m}$ wide by $48 \mathrm{~m}$ long and $4 \mathrm{~m}$ tall ( $24 \mathrm{ft}$ wide, $144 \mathrm{ft}$ long, $12 \mathrm{ft}$ tall). The specifications for HD-5 fuel grade propane require a minimum concentration of $95 \%$ propane. A sample of the fuel was analyzed after each test to verify its content.

The congestion level was in the "low" configuration with no pipes added and a resulting low volume blockage ratio (e.g., volume occupied by the obstacles divided by the volume of the rig) of 5.8\%. The results of the first full-scale test resulted in a DDT approximately half way down the rig (see Figure 12 and Figure 13). A repeat of this test, using a different batch of commercial grade HD-5 propane, similarly resulted in a DDT; however, the DDT occurred approximately two modules further down the rig (see Figure 14).

Advanced methods for tracking the flame front position with distance were employed to accurately determine the flame speed along the rig. Figure 15Error! Reference source not found. shows an automated flame speed calculation along defined lines of interest. Results have shown that the measured flame speed was almost independent of the line along which the flame front was tracked. Figure 16 shows the measured flame positions versus distance and also confirms that the two tests transitioned at slightly different locations. After transition, flame speeds of approximately 1700 $\mathrm{m} / \mathrm{s}(5,500 \mathrm{ft} / \mathrm{s})$ were shown to be close to the theoretical Chapman-Jouguet detonation velocity.

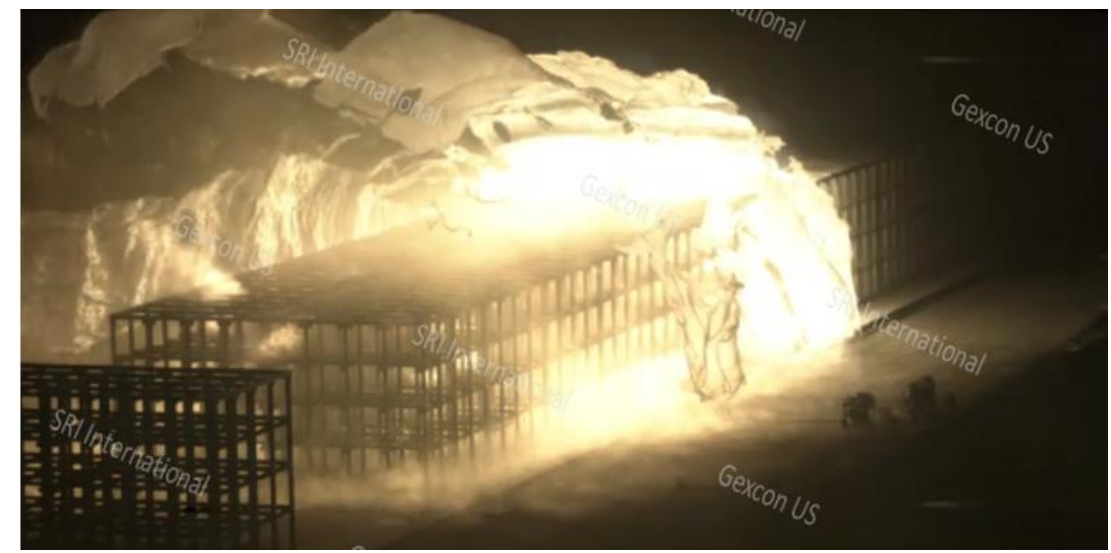

Figure 12-Test \#5 camera screen capture. 

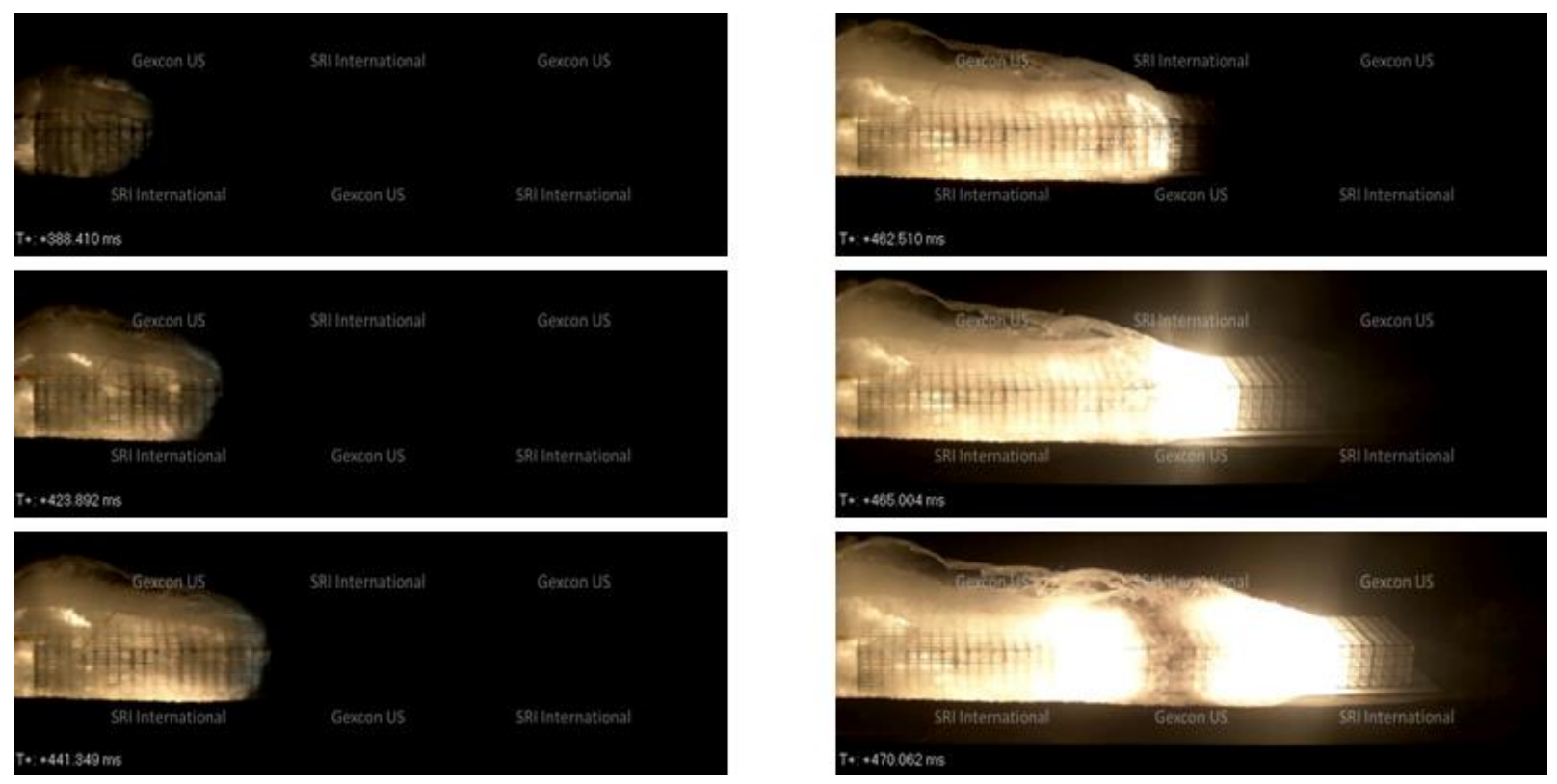

Figure 13-Test \#5 high-speed video screen captures of the DDT (side view).
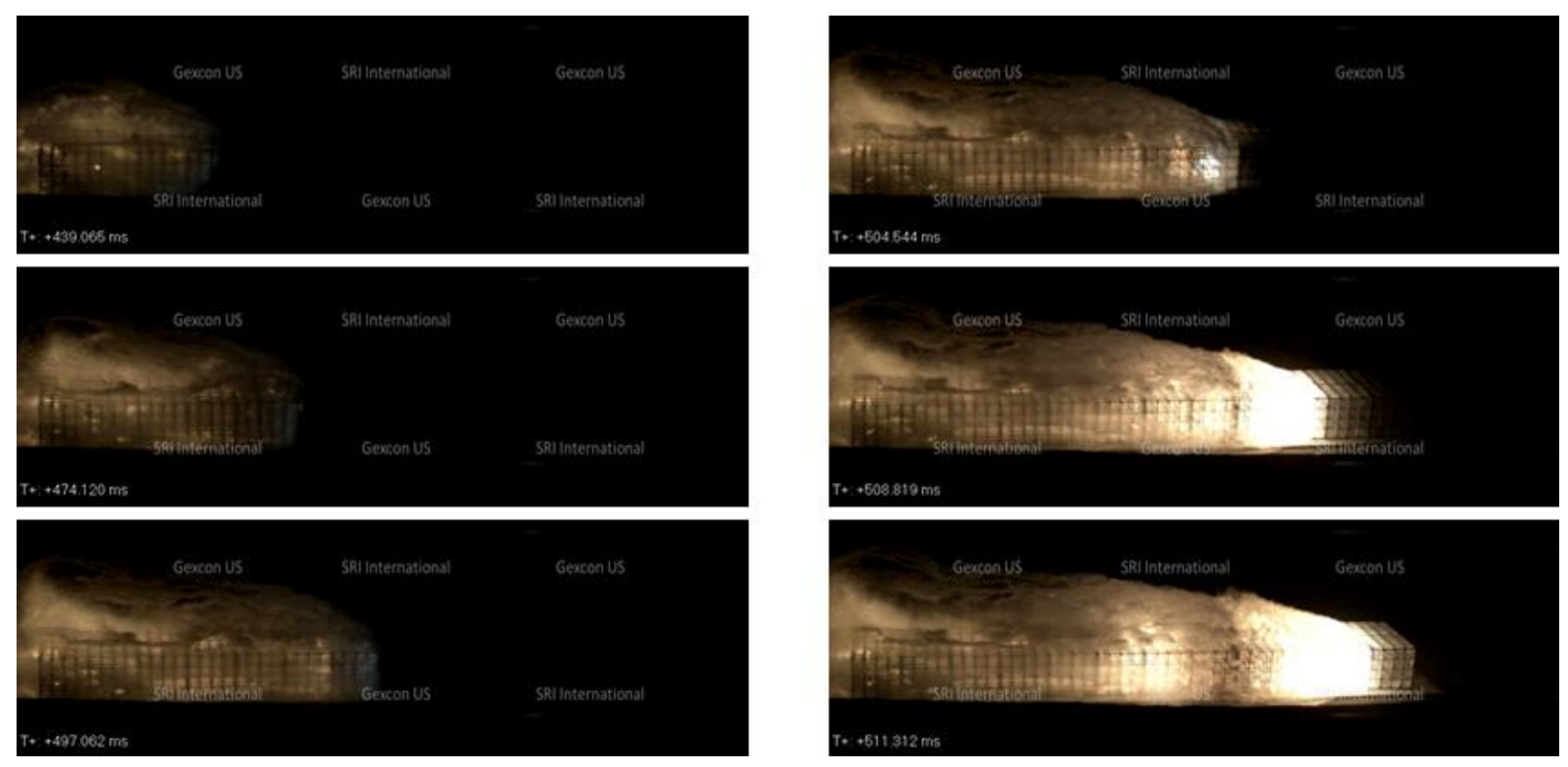

Figure 14-Test \#6 high-speed video screen captures of the DDT (side view). 

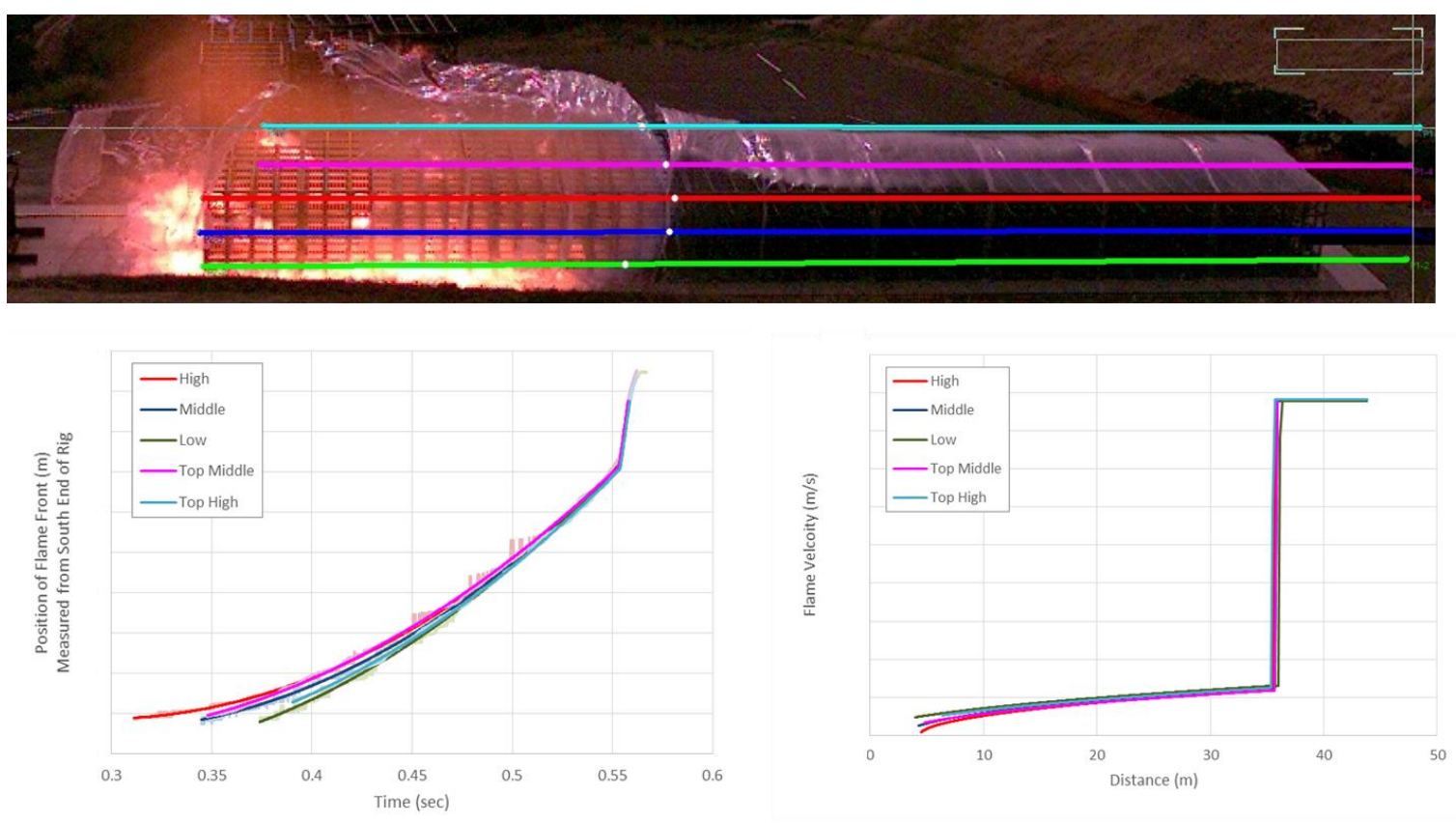

Figure 15-Flame speed data analysis.

\section{Modules - "Low" Congestion}

Stoichiometric Propane

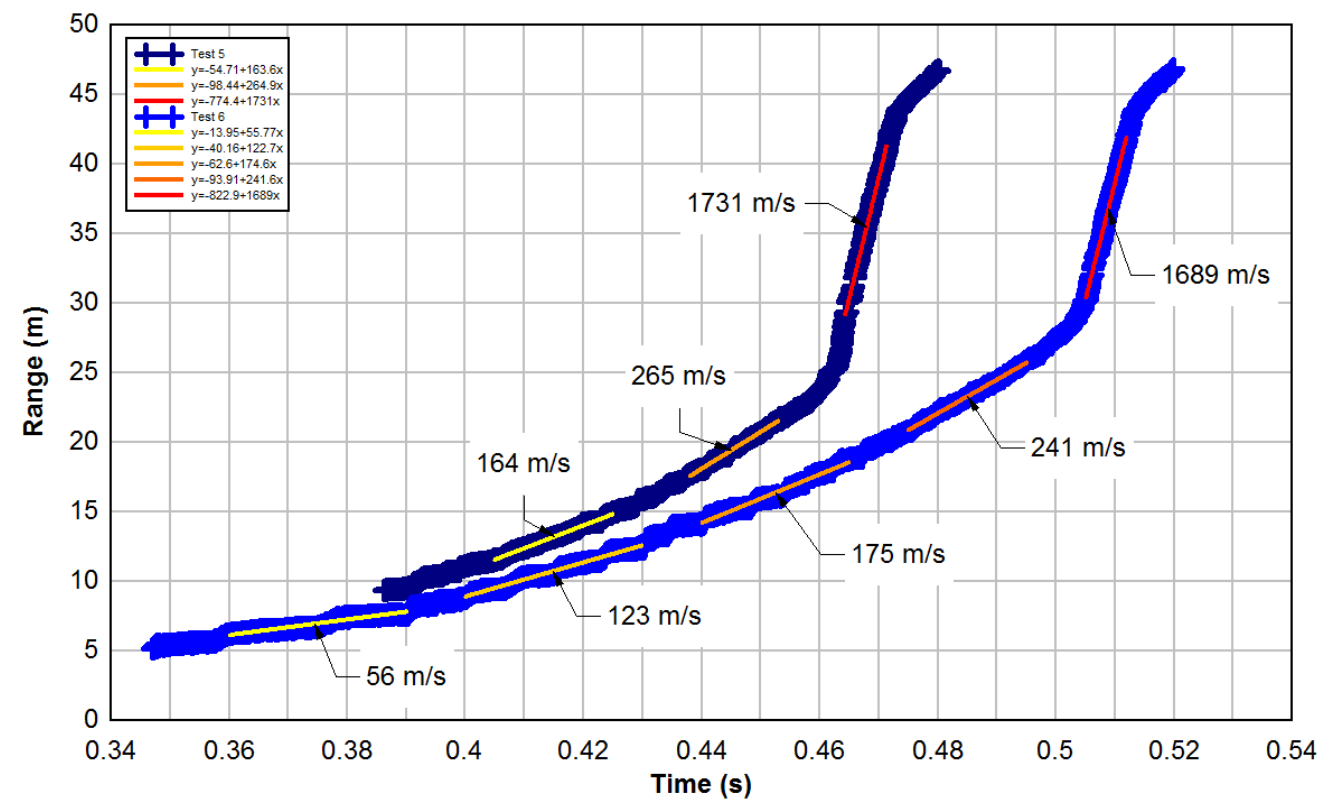

Figure 16-Flame position versus distance in the rig for Tests \#5 and \#6.

Additional tests were performed in order to better understand the potential reasons that propane exhibited a deflagration-to-detonation transition for "low" congestion conditions. More specifically, the effect of the plastic sheet and propane purity were evaluated. The next test conducted (Test 7) was with thinner plastic sheets ( 2 mils instead of 4 mils) on the first 3 rows. This would alleviate some initial confinement during initial flame development. The end result was nearly identical to that of Test 6 as shown in Figure 17 and Figure 18. Test 8 was conducted with a higher purity propane ( 97.5\%); however, the fans were 
inadvertently left in operation during the test. As expected, the initial turbulence created by the fans allowed the flame to transition to detonation much early than the tests without initial turbulence.

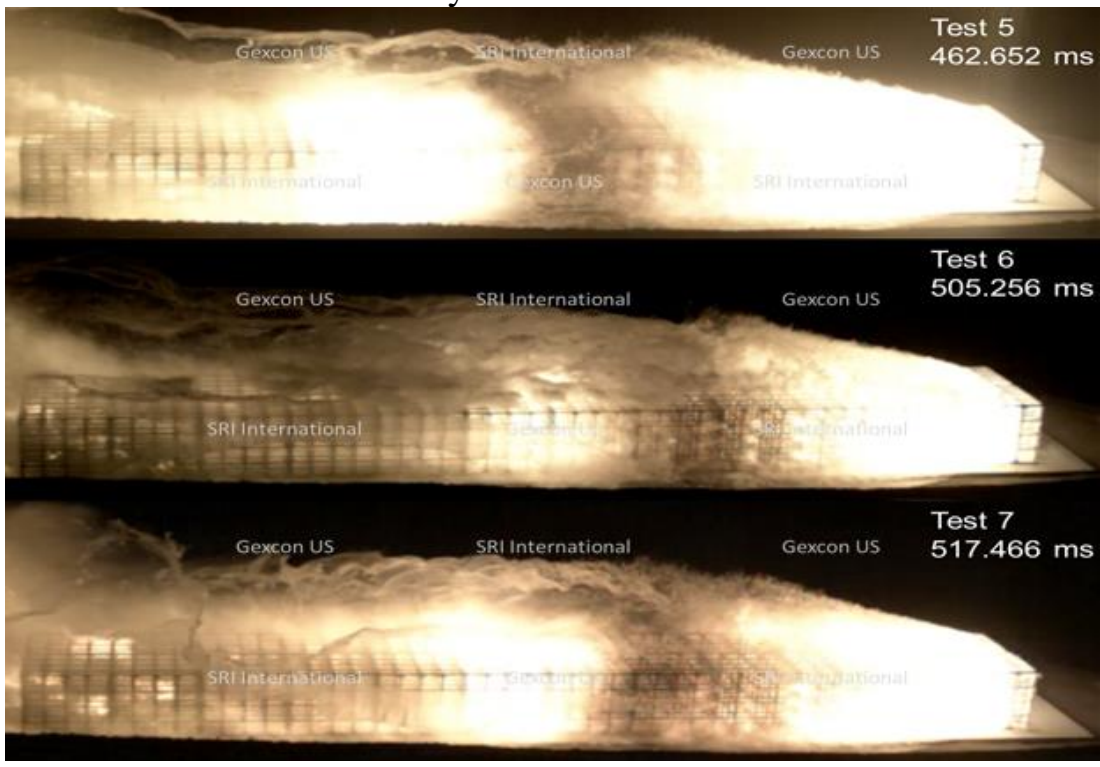

Figure 17-Comparison of flame endpoints.
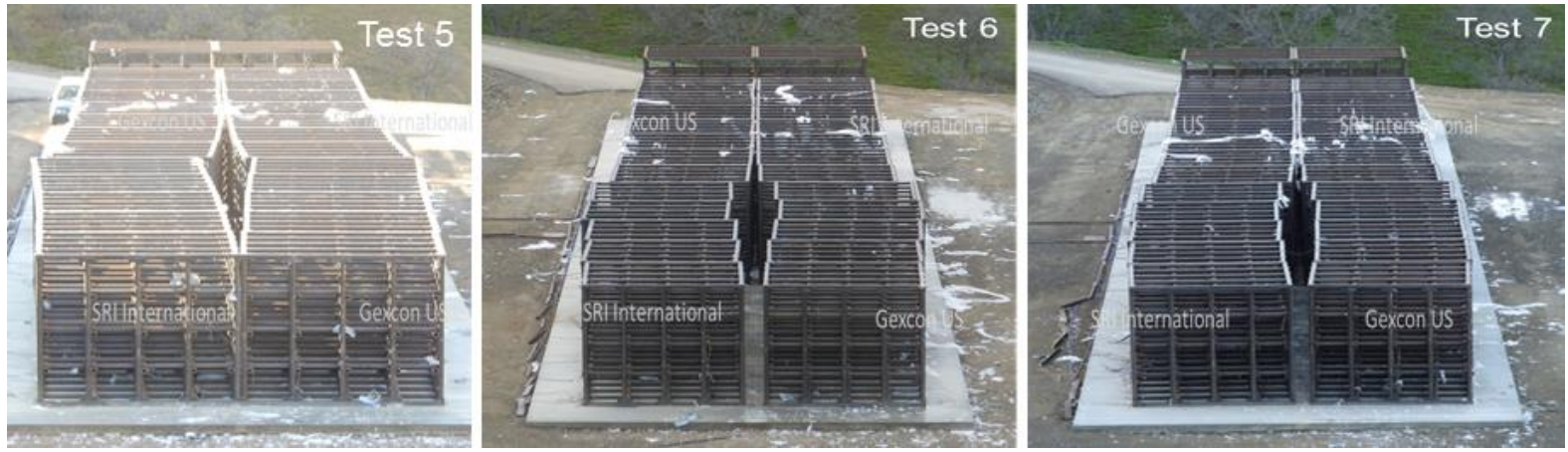

Figure 18-Damage comparisons for Tests 5 through 7.

Test \#9 was conducted with a near stoichiometric concentration of methane $(\varphi=0.92)$. This was the first test conducted with the full 30 module array and with methane as the fuel source. The thinner 2 mils plastic was used for this test. Again, the module array was uncongested for the same volume ratio of $5.8 \%$ that were used in Tests 5-8. This tests did not result in a DDT and the resulting flame speed reached a constant value of $75 \mathrm{~m} / \mathrm{s}$.
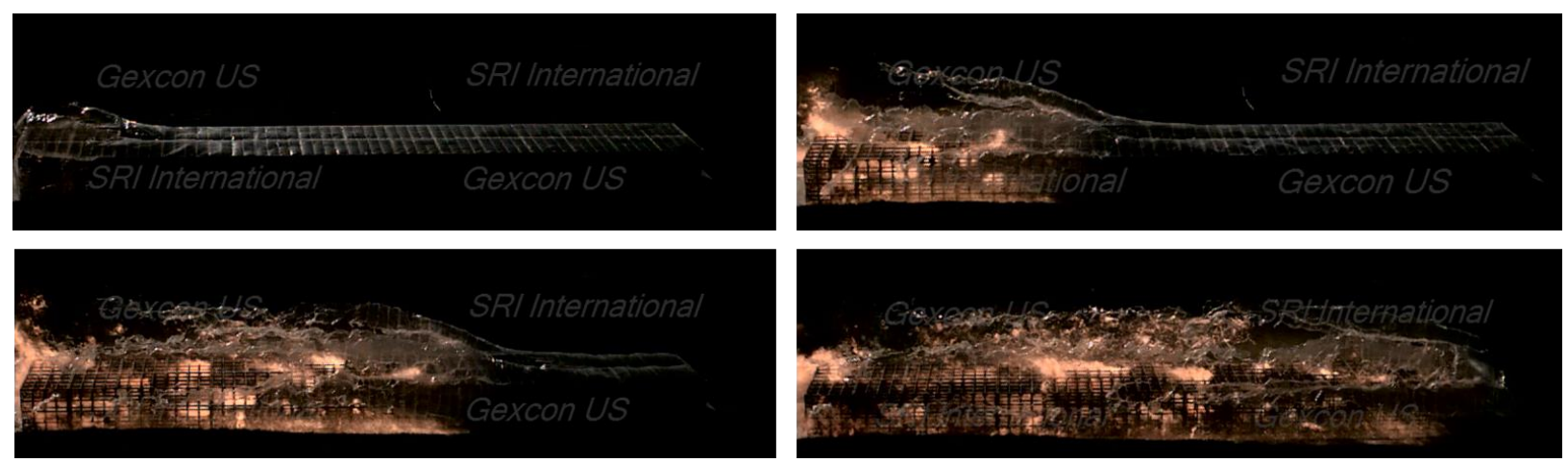

Figure 19-Test \#9 high-speed video screen captures of flame front. 
Tests \#10 and \#11 were conducted with lean and rich mixtures of propane respectively. The equivalence ratios at ignition were 0.81 and 1.35 . They were also conducted in the full 30 module uncongested array. Similar to methane, each of these tests did not result in a DDT.

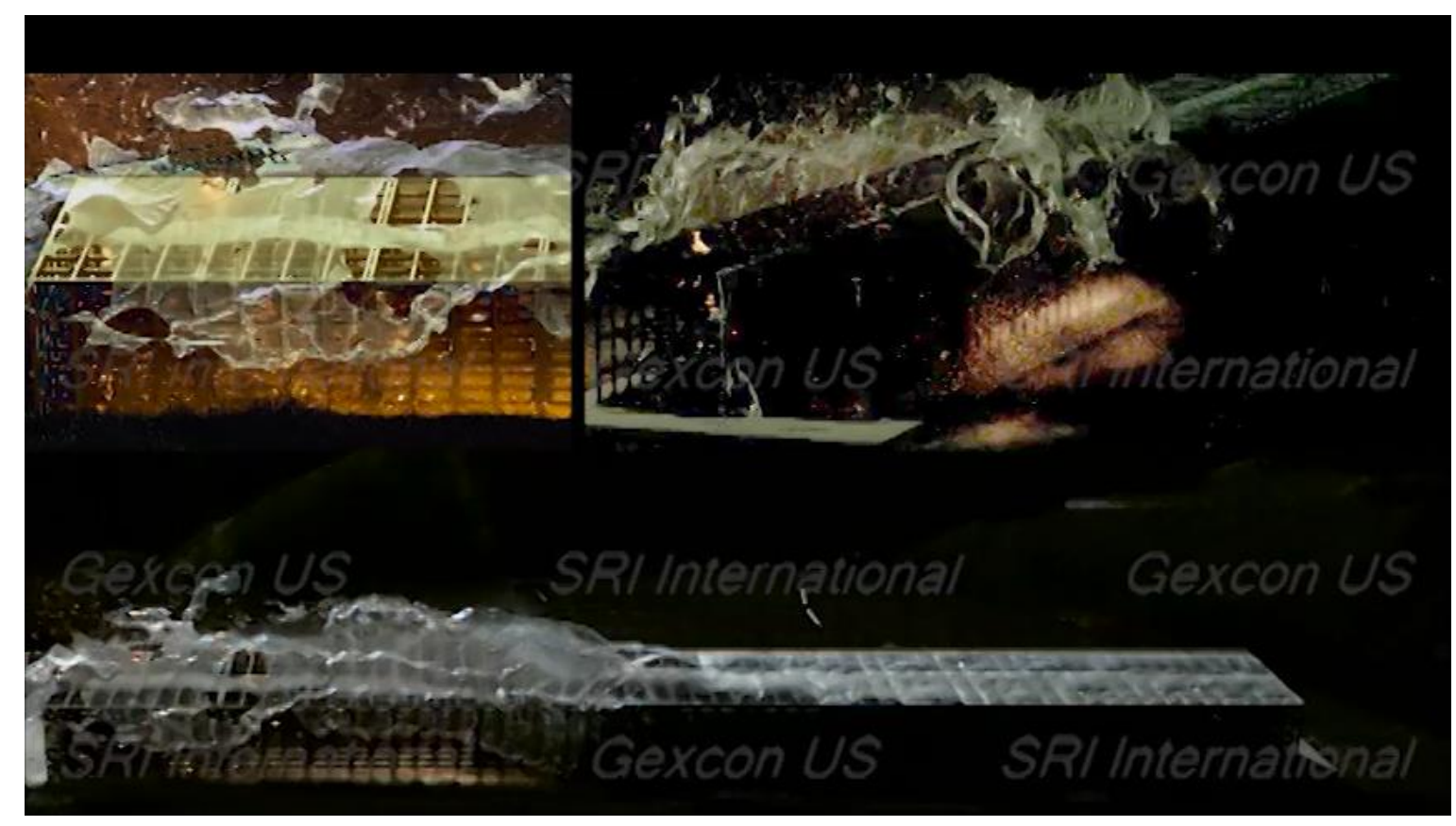

Figure 20- Test \#10 high-speed video screen captures of flame front.

One final test (\#12) with the higher purity propane was conducted in order to eliminate the effect of the containment plastic. In this test, a mortar was launched connected with wire to the upper corners along the entire length of the congestion rig. The timing of the system was set to cut the plastic ahead of the flame front and eliminate the "weight" of the plastic. With the mortar system in place, the higher purity propane again had a deflagration-to-detonation transition, indicating that neither the purity of the propane nor the confinement of the plastic had an effect on the results for propane.

Beginning with Test \#13, the congestion in the modules was changed to the "high" configuration. This configuration added numerous 7" and 2" pipes into each module with different horizontal and vertical orientations for two-dimensional congestion. The resulting volume blockage ratio was approximately $10.9 \%$. Tests were scheduled for stoichiometric methane, lean and rich propane and mitigation tests with an inerting agent present in the modules for methane.

Test \#13 was performed with near stoichiometric methane $(\varphi=1.05)$. The results indicated that for this level of congestion and methane/air mixture, the velocity of the flame front reached fast deflagration speeds of approximately $250 \mathrm{~m} / \mathrm{s}$. When tests using lean $(\varphi=0.90)$ and rich mixtures $(\varphi=1.35)$ of propane were performed on the same high obstacle density rig, they both resulted in detonation.

Interestingly and differently from previous tests, the current results indicate that the current mixtures transition to detonation at flame speeds near the speed of sound in the unburned mixture (see Figure 21). In fact, the average transition velocity for all the tests that transitioned to detonation was approximately 250 $\mathrm{m} / \mathrm{s}$ and the resulting detonation velocities between $1600-1800 \mathrm{~m} / \mathrm{s}$. Other investigators report flame speeds of approximately $600 \mathrm{~m} / \mathrm{s}$, which is closer to the speed of sound in the burned mixtures, to allow for DDT (see e.g. McKay et al, 1988). 


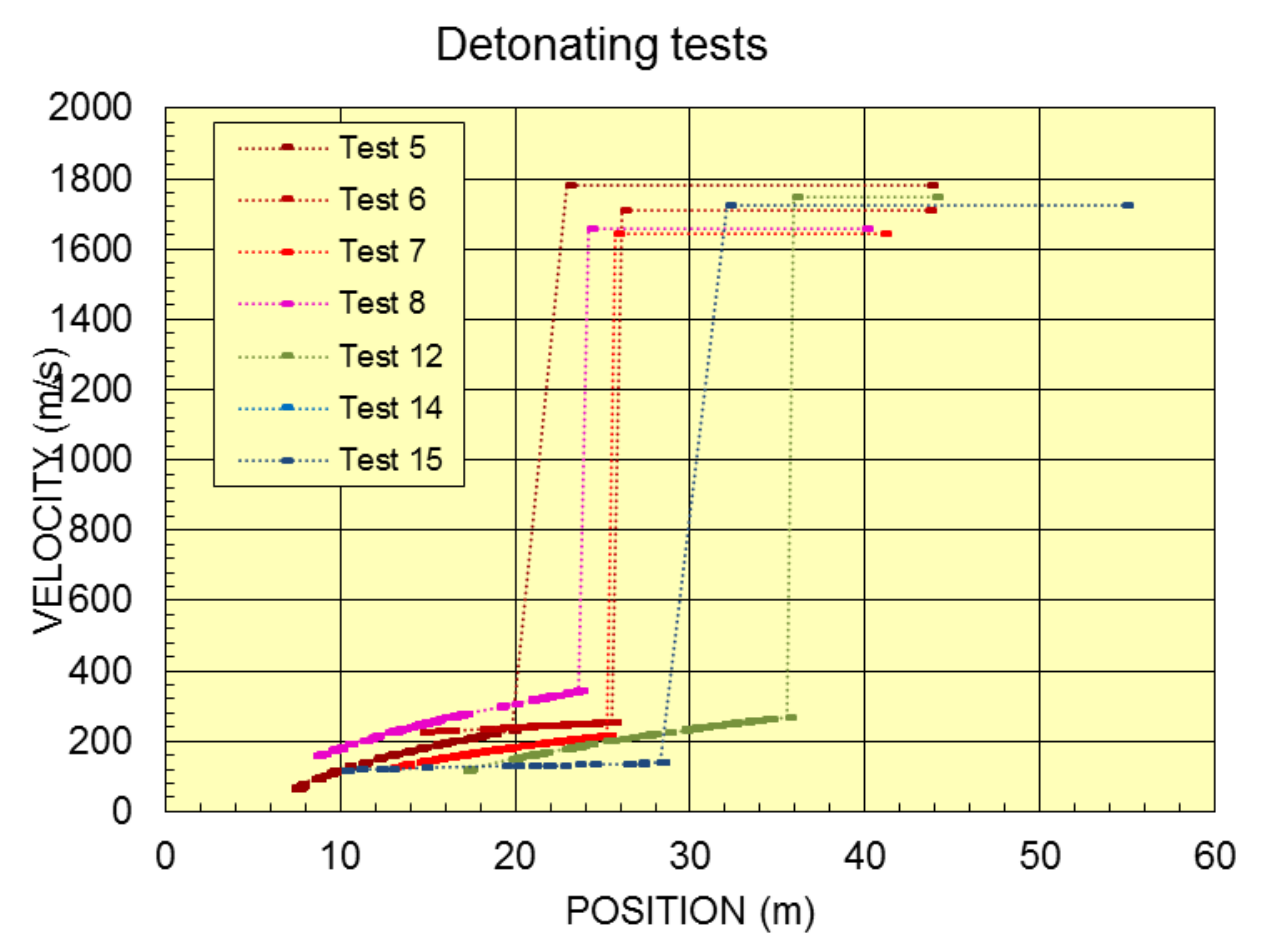

Figure 21: Flame speed results for tests that transitioned to detonation.

To increase the amount of information available from the high speed video records, a simple enhanced image analysis technique was applied to the images. The first image, taken prior to the ignition event, is designated as a reference image. The first, original image, and every other image in the series is reduced to grayscale, and converted into arrays with numerical pixel intensities. Next, the reference image array is subtracted from each subsequent image array and reproduced into an image, as shown in Figure 22. This example image was taken a few instants after a detonation occurred and a pressure wave was released.

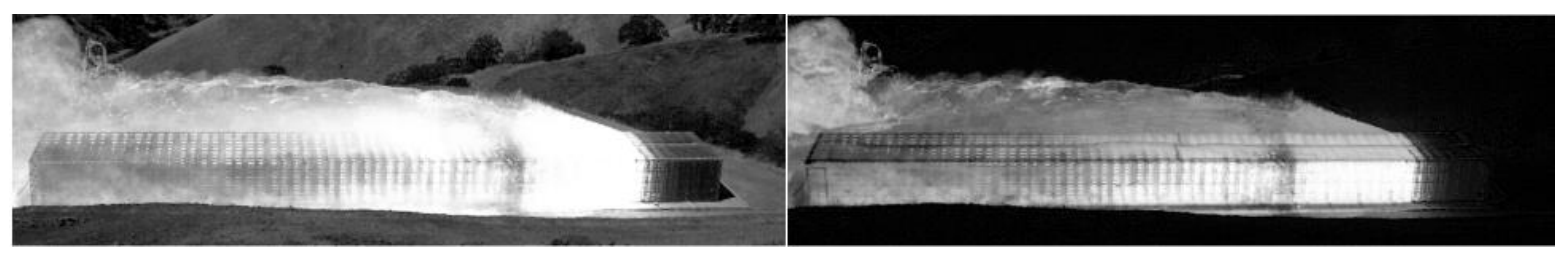

Figure 22. Original grayscale image (left) and the same image with reference pixel intensities subtracted (right)

The new image illustrates the change in pixel intensities from the reference to the current image. This focuses the image analysis on the flame and potential shockwaves because, in this time frame, the rig itself and the background are stationary and lighting is constant. Alternatively, to visualize this data in a different way, the pixel intensities may be plotted in a color map to emphasize where pixel differences are large, and this is shown in Figure 23. 


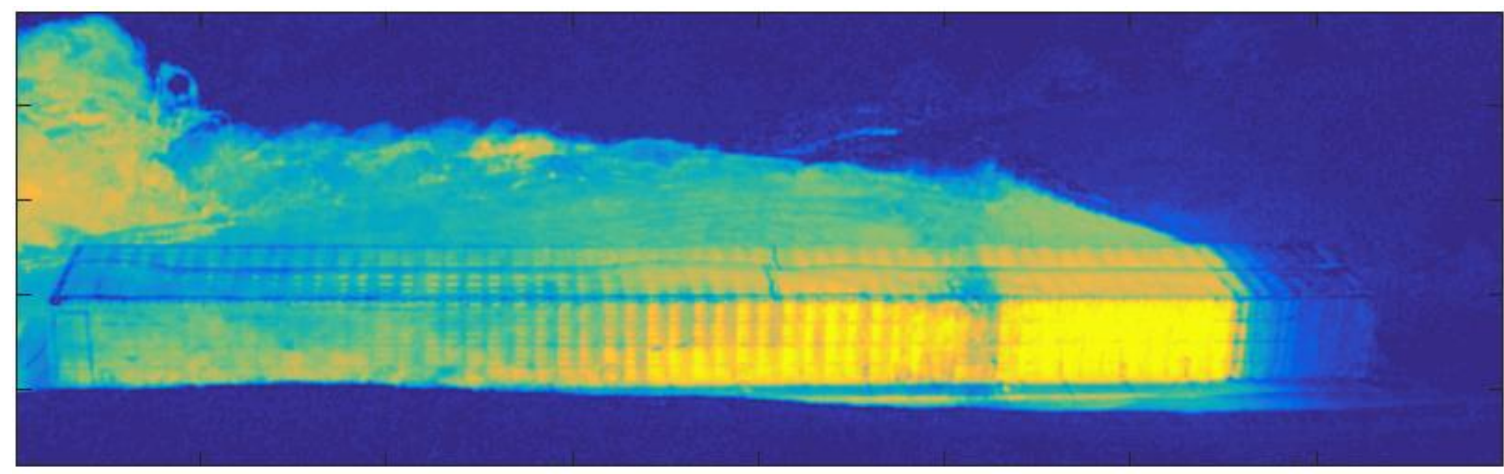

Figure 23. Color map of pixel intensity differences

This analysis may then be taken a step further by taking the spatial gradients of pixel intensities in both the $\mathrm{x}$ - and $\mathrm{y}$ - direction. This emphasizes discontinuities and rapid changes in the pixel intensity field. Features like the flame front and shockwaves then become readily visible and much easier to accurately track. Figure 24 shows the color map of the sum of the spatial gradients in each direction of the image from Figure 24. For scaling of fainter features like the shock front, the square root of the magnitude of the gradient is taken.

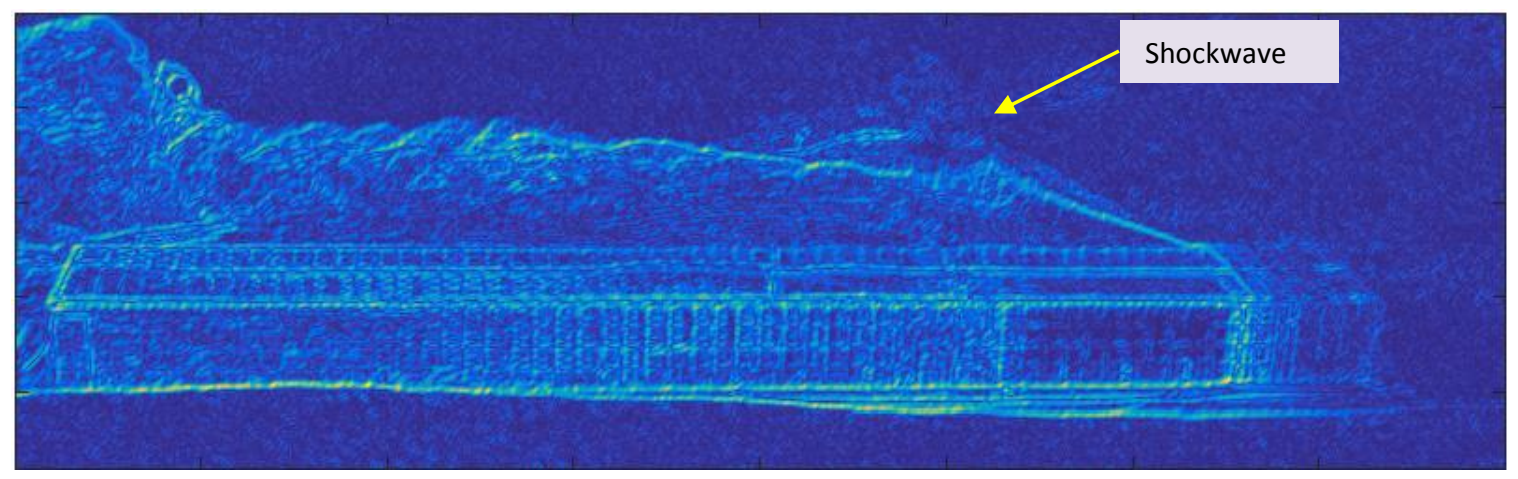

Figure 24. Color map of pixel intensity gradients

Clearly visible in this image is the flame front itself, but also visible is the shockwave emanating from the point of detonation as indicated in the figure. The shockwave creates a discontinuity in density of the air as it travels through the medium. Since density and refractive index are closely related, the shock changes the refractive index of the air it occupies. This in turn will alter the pixel intensities by a small amount in the image. This change may be difficult to detect directly, but when examining gradients, it becomes more clear due to the discontinuous nature of the shock front.

To validate this analysis method, position of the flame front as measured by this technique is compared with ion pin position versus time data. Data is extracted from a single horizontal line, on the side of the rig, across the entire resolution of the image for each successive image in the series. A contour plot is then created by assembling the horizontal slice from each image across time. This is similar in principle to a streak camera and makes tracking of the flame front very straightforward. The following plots show only the $\mathrm{x}$-component of the gradient, as we are only concerned with propagation of the flame in that direction.

Figure 25 shows this comparison for Test 13. In this test, no detonation was observed, rather the flame front accelerated until the end of the rig. This figure shows that this image analysis agrees with ion pin data quite well, and accurately captures the progression of the flame front throughout the deflagration event. 


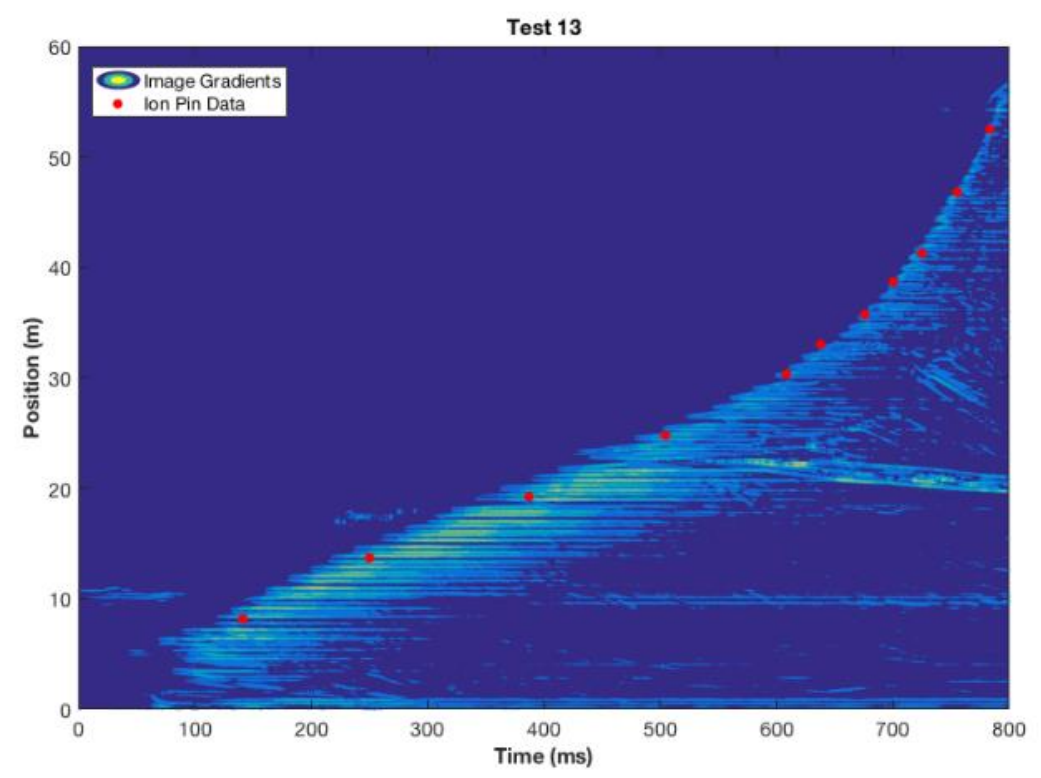

Figure 25. Image gradients and ion pin data from Test 13.

The image gradient plot and ion pin data for Test 15 are shown in Figure 26. In this test, deflagration lasted for approximately $2 / 3$ of the length of the rig before a transition to detonation was observed. Again, the image analysis outlined previously, well captures both the initial deflagration, flame front acceleration, and detonation. The flame front positions measured this way agree very well with ion pin data, demonstrating the effectiveness of this technique for multiple different types of events.

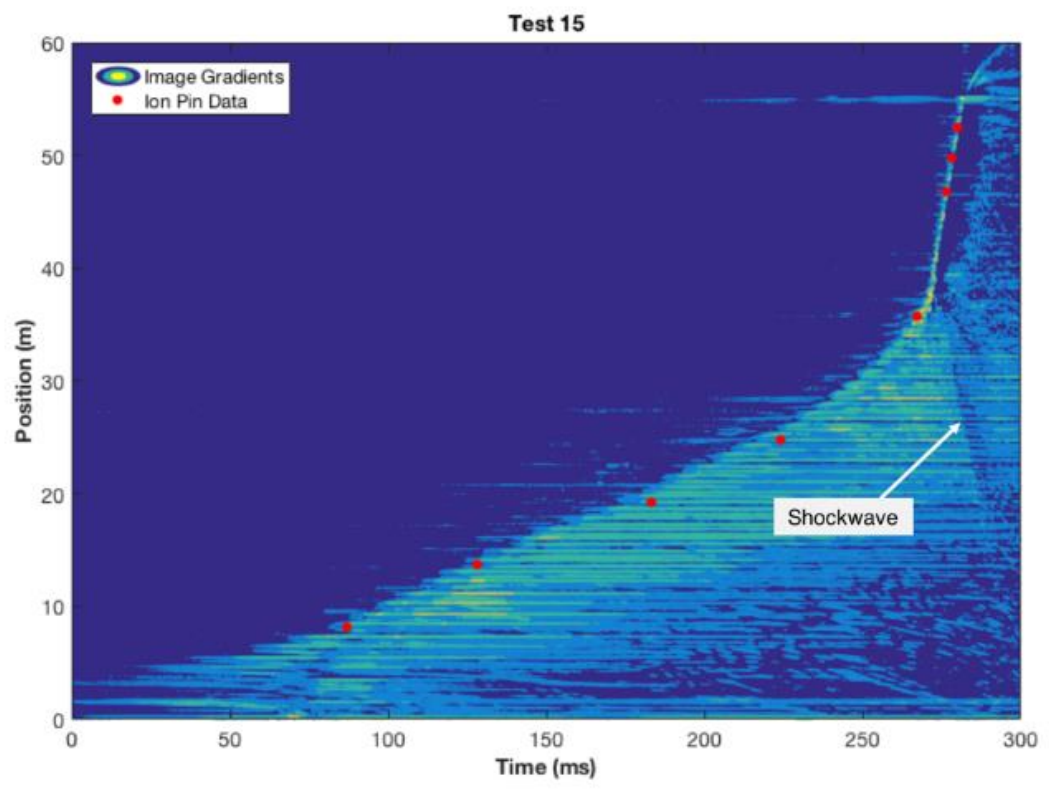

Figure 26. Image gradients and ion pin data from Test 15.

An additional piece of information measurable with this analysis is the formation and propagation of the pressure wave following detonation. The wave is seen to propagate back towards the ignition source after detonation occurs, and is labeled in Figure 26. The discontinuity in the image gradient plotted at that point indicates the presence of the shock. 


\section{Mitigation Tests - preliminary results}

The mitigation tests were recently performed using the Vapor Cloud Explosion Mitigation by Inhibition System (VEMIS) technology developed by TOTAL. The main principle of this system relies on the direct injection of solid inhibitor into the flammable cloud, in a type of "curtain" protection. The mitigation tests were performed with the rig in the "high" congested configuration using a plastic sheet that was not cut. In fact, the winds at the time of testing were quite strong and the plastic was held in place with a stronger mechanism at the bottom than previous tests. As the full scale, "high" congestion test with methane (Test \#13) did not result in a detonation, it was chosen as the "base" case to test the mitigation system. The idea of the mitigation was to effectively apply a "mitigation" curtain using a solid inhibitor as shown in Figure 27.

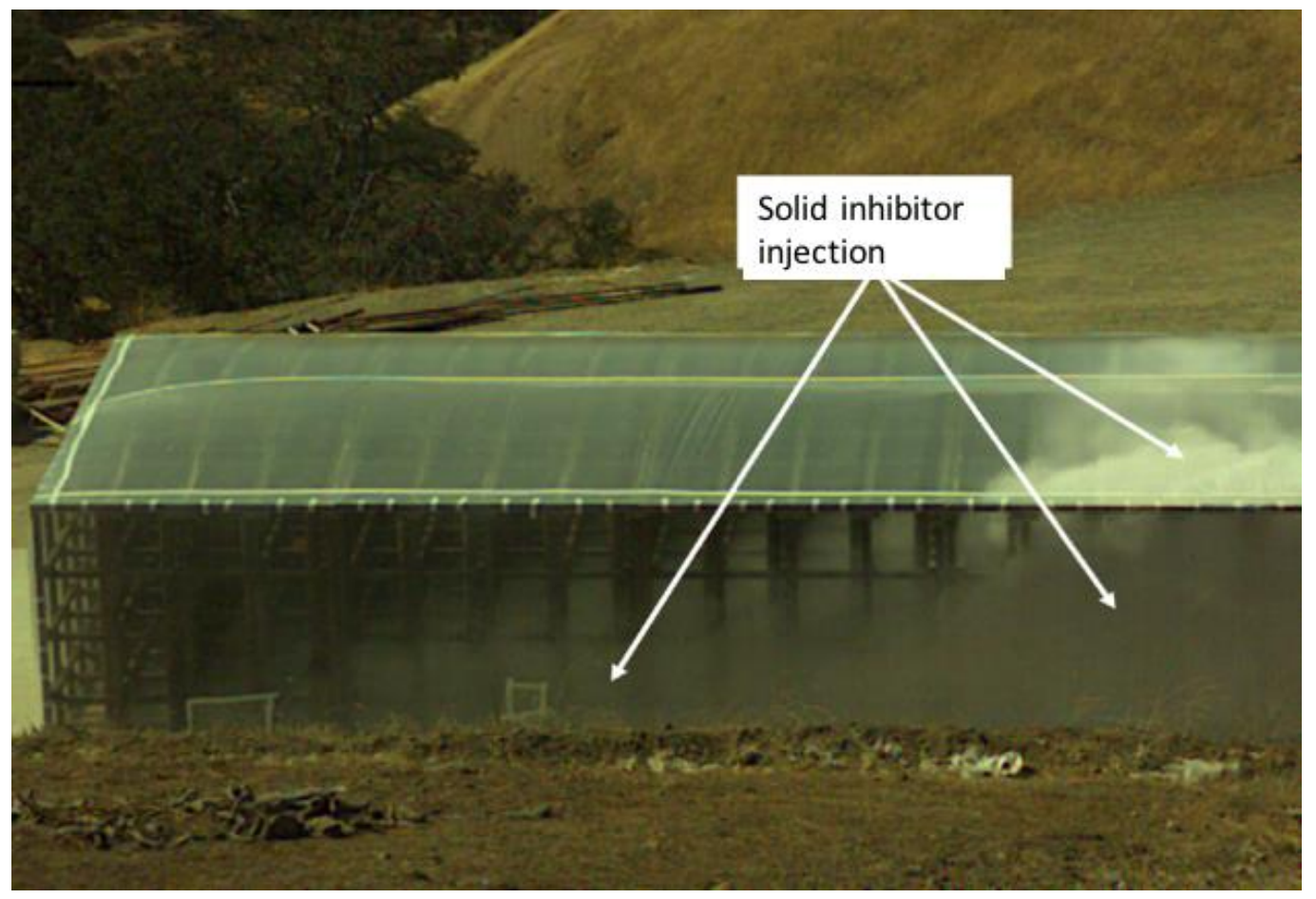

Figure 27: Solid inhibitor "curtain" applied across a row of modules

The first test (Test \#16) applied the inhibitor in the last third of the rig. This test resulted in methane propagating at nearly $800 \mathrm{~m} / \mathrm{s}$ after only 25 meters. It has been postulated that the mechanism used to retain the plastic may have created an initial confined that resulted in a low velocity detonation, or as other authors ${ }^{10}$ have termed a "quasi" detonation resulting from severe pressure losses inflicted by the obstacles. Once the quasi-detonation impacted the inhibitor curtain, the velocity decreased considerably down to 250 $\mathrm{m} / \mathrm{s}$ yet the shock wave continued into the unburned mixture ahead of the flame (see Figure 28 and Figure 29). The flame was not fully extinguished by the inhibitor curtain and when it reached the flammable mixture behind the shock front, it accelerated up again to near quasi-detonation velocities at the end of the rig.

This is a unique case in which a mitigation system was deployed in an attempt to slow or stop the flame front. The order of events in this first mitigation test were as follows: (1) gas ignition and deflagration, (2) flame front accelerates to a constant low velocity detonation, (3) flame front encounters mitigation region and greatly decelerates, (4) flame front passes mitigation region and accelerates back up to a low velocity detonation near the end of the rig.

The image gradient plot and ion pin data for Test 16 are shown in Figure 30. It can be seen that image gradients capture all four different regions of the event very well, and show excellent agreement with the 
ion probe data points. What is more interesting, is the information that the gradient images provide that the ion probes do not. After the flame front encounters the mitigation region, it slows down, but the pressure wave generated by the quasi-detonation does not. Therefore, the pressure wave separated from and outpaced the flame front in this region, which is seen quite clearly in the gradient images. Figure 31 gives a more detailed look at the detachment of the pressure wave in the mitigation region. 

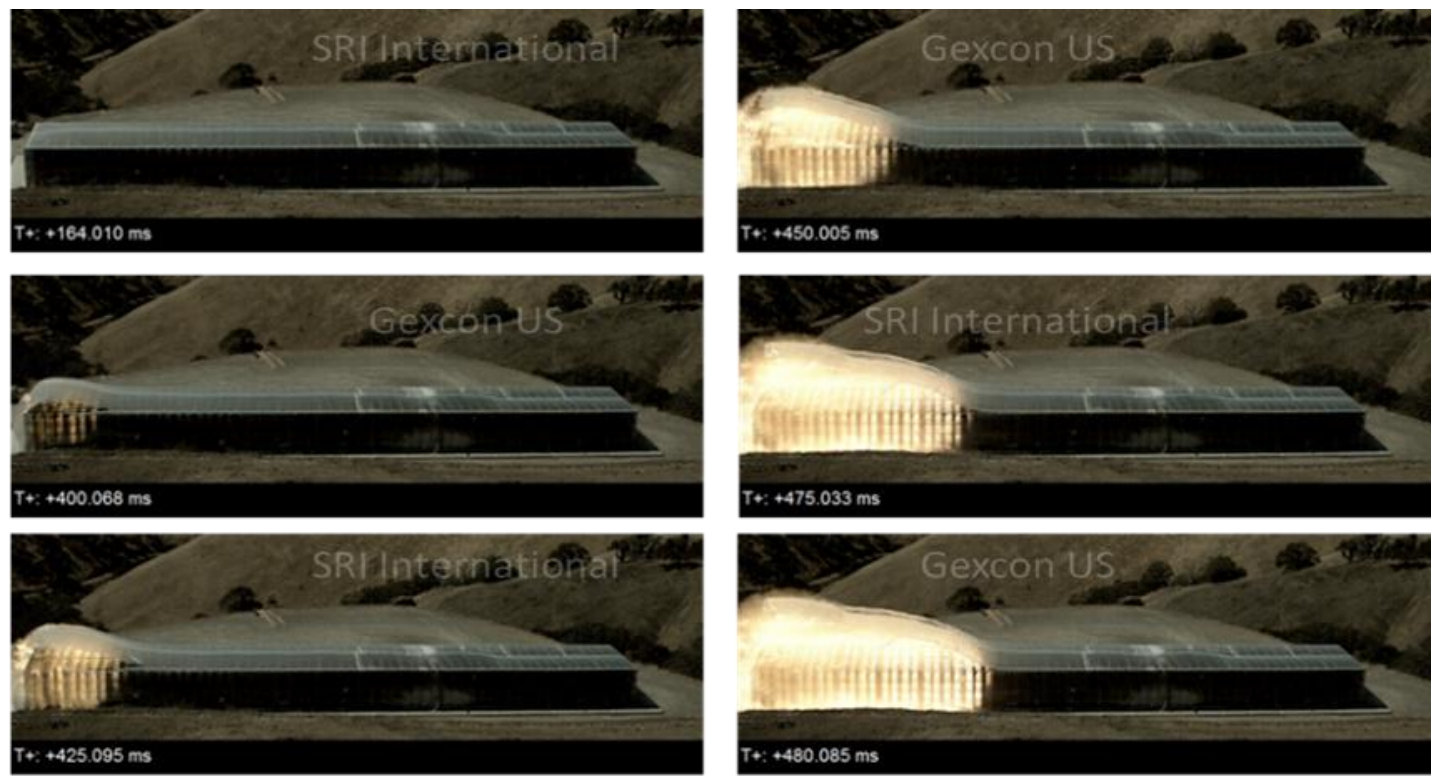

Test 16 - Deflagration with Flame Acceleration-Part 1 Screenshots
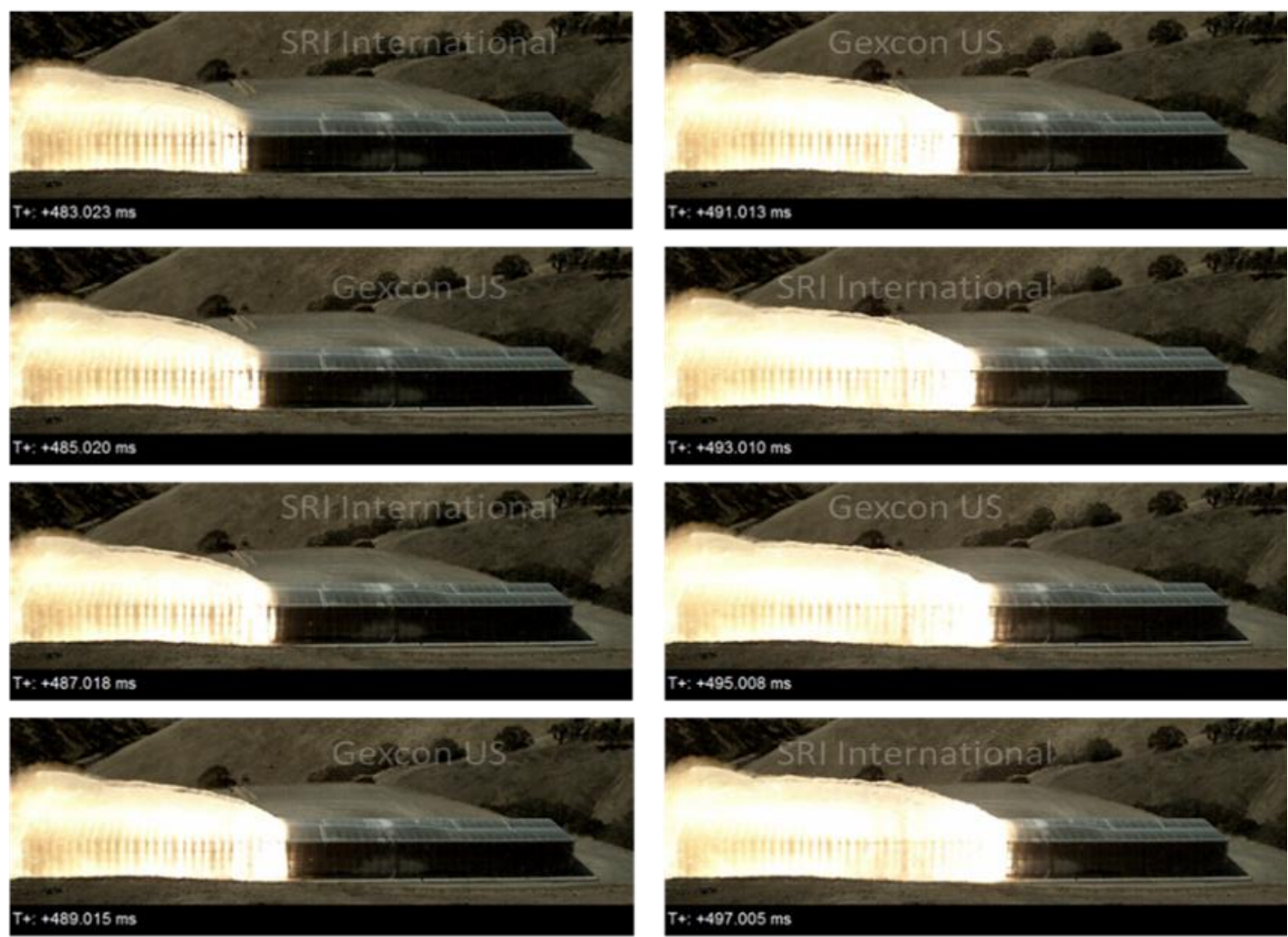

Test 16 - High Speed Constant Velocity Deflagration - Screenshots

Figure 28: High congestion stoichiometric methane with mitigation system. 


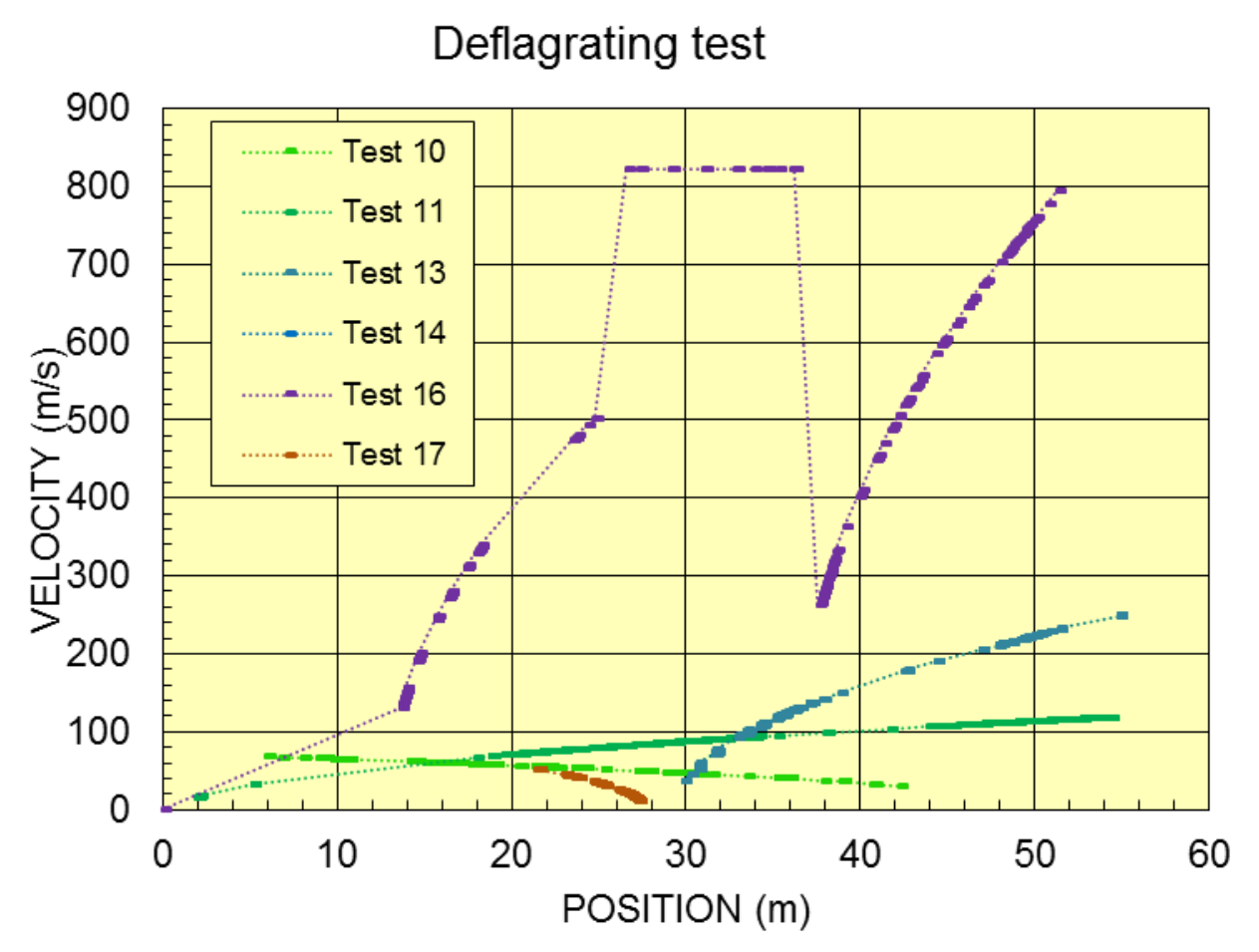

Figure 29: Flame speeds of tests that resulted in deflagrations only

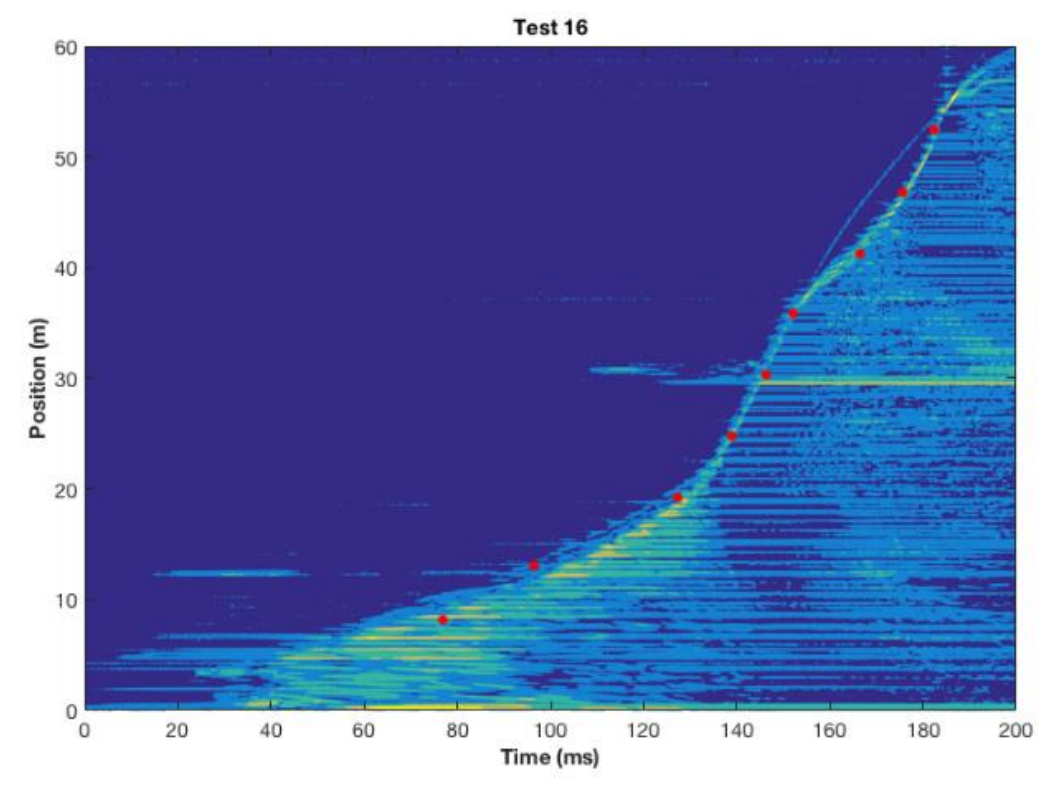

Figure 30. Image gradients and ion pin data from Test 16. 


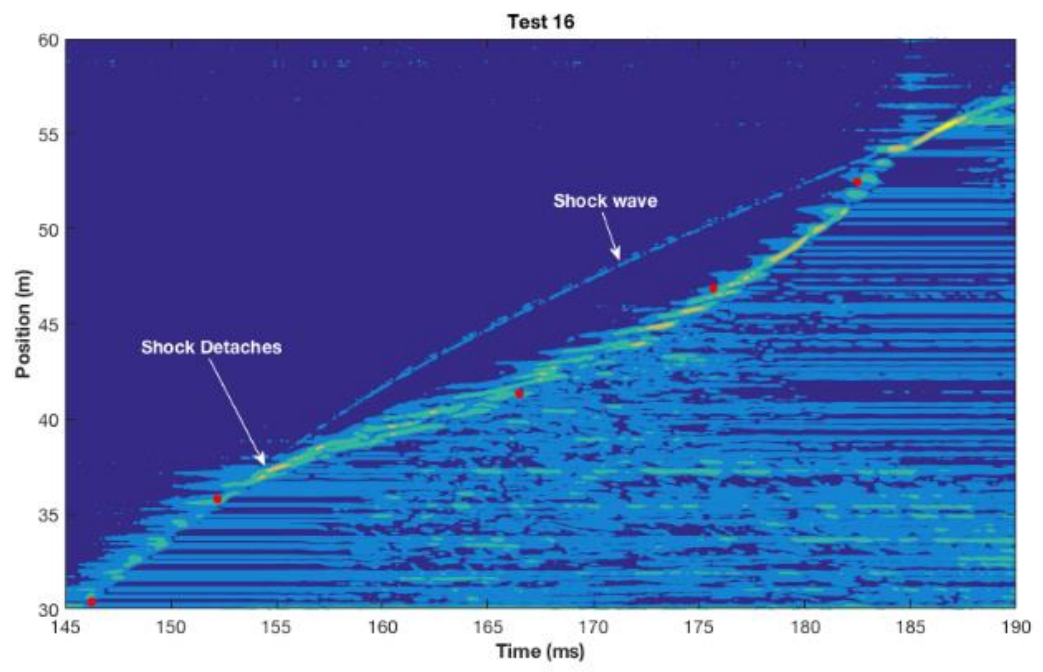

Figure 31. Detail of shock detachment in Test 16.

The pressure wave is shown to continue at approximately the same velocity while the flame front decelerates, causing the separation between the two. The flame front is next observed to accelerate again, until it rejoins the pressure wave at the end of the rig. This type of information - the detachment of the pressure wave, speed of detached pressure wave, and rejoining with flame front - were previously unavailable with ion pin data or traditional high speed video alone, which shows the value and power of this simple technique.

In the second mitigation experiment (Test \#17), a shorter test rig was used and the mitigation region was positioned considerably closer to the ignition point. The flame front hit the mitigation region and drastically decelerated. When the front left the mitigation region, it was able to redevelop into an approximately planar wave in the rig. What may be concluded from both ion pin and image analysis is that the flame front experiences a drastic deceleration as it passes through the mitigation region. The goal of this research is to effectively prevent detonations from occurring.

Each of the tests being performed has been replicated in the FLACS CFD software package in an effort to further validate the solver. Any potential weaknesses will be uncovered and addressed in a future update package.

\section{FUTURE WORK}

As the award comes to a close there are several topics that will required to be studied further, either through further grants or joint industry projects. Current ideas include the studying the following topics.

The width of the congested area appears to play a significant role in the likelihood of DDTs. We would like to conduct tests where the width of the congestion is halved to less than four meters and compared with the results from the current study that use a 7 meter wide test setup.

Separation gaps have been used in inherently safer designs but are not fully tested at the large scale. Separation gaps and distance between probable explosion domains have a significant effect on reducing the rate at which flames burn, and can essentially "decouple" the acceleration effects in two neighboring domains. They have been used both in land based siting studies and as separation gaps for offshore facilities. No large-scale tests with wide (greater than seven meter) congestion blocks have been used in prior tests.

Testing active mitigation measures at the large scale would have enormous benefit. For these proposed tests, if gas is detected, active mitigation measures such as water deluge or solid inhibitors would be 
deployed to reduce the flame acceleration and rate of burning, and effectively mitigate explosion consequences. Even if combustion has started, the current study demonstrated that DDTs could be mitigated by deploying solid inhibitor - additional investigations should be conducted with water and inhibitor to study the effects.

With the modules already constructed and available at the test site, interesting tests could be conducted with realistic congestion. The modules are flexible, realistic congestion ranged from 24-inch vessels down to 2inch pipes can be installed in the modules to verify the effects of realistic congestion as compared to consistent and repetitive congestion performed in this first phase.

An inherent flaw in testing uniform concentration fuels is that they do not truly represent conditions that would be present at the time of an incident. Unintentional gas releases oftentimes occur from pressurized equipment or piping on offshore or onshore facilities, which result in inhomogeneous gas clouds with nonuniform concentration gradients. Understanding the likelihood of DDT within these realistic clouds at the large scale has not been studied, as well as the effect of the initial turbulence caused by the released gas.

\section{CONCLUSIONS}

Large scale testing concluded in September 2016. The data available at the time of this writing, indicate that DDTs at large scales may be easier to obtain than from previous experiments performed in smaller test rigs. This work has shown that critical validation blocks upon which future tools can be developed are necessary. Flame speed and overpressure CFD software packages require modification to appropriately model this phenomenon. There is still more work required to fully understand the onset of DDT and other factors would affect flame and overpressure development for realistic and practical applications.

\section{REFERENCES}

${ }^{1}$ Bakke, J. v. W. K. H. P. \&. B. B., 2010. A study on the effect of trees on gas explosions. Journal of Loss Prevention in the Process Industries, pp. 23, 878-884.

2 Johnson, D., 2010. The potential for vapour cloud explosions. Lessons from the Buncefield accident. Journal of Loss Prevention in the Process Industries, pp. 23, 921-927.

${ }^{3}$ Johnson, D., 2012. Characteristics of the Vapor Cloud Explosion Incident at the IOC Terminal in Jaipur, 29th October 2009. Houston, AIChE.

${ }^{4}$ Middha, P. H. O., 2008. Predicting deflagration to detonation transition in hydrogen explosions. Process Safety Progress, pp. 27 (3), 192-204.

${ }^{5}$ Puttock, J., 2013. Gas explosion modelling with PDRFoam. Cardiff, UK Explosion Liaison Group.

${ }^{6}$ Tang, M. B. Q., 1999. A new set of blast curves from vapour cloud explosions. Process Safety Progress, pp. (18) 235-240.

${ }^{7}$ U.S. Chemical Safety and Hazard Investigation Board, 2015. Caribbean Petroleum Tan Terminal. Explosion and Multiple Tank Fires, Report No. 2010.02.I.PR: s.n.

${ }^{8}$ Van den Berg, A., 1985. The multi-energy method. A framework for vapour cloud explosion blast prediction. Journal of Hazardous Materials, pp. (12) 1-10.

${ }^{9}$ van Wingerden, K., 2008. On the possibility of DDT in vapor cloud explosions. New Orleans, AIChE.

${ }^{10}$ Lee, J.H., Knystautas, R. and Freiman , A. . High speed turbulent deflagrations and transition to detonation in H_2-Air mixtures. Combust. Flame, 56(2):227-239, 1984. 